\title{
Diphenylurea-derived cytokinin oxidase/dehydrogenase inhibitors for biotechnology and agriculture
}

Jaroslav Nisler ${ }^{1,2,4^{*}}$, David Kopečný3, Zuzana Pěkná ${ }^{3}$, Radka Končitíková ${ }^{3}$, Radoslav Koprna $^{4}$, Nino Murvanidze ${ }^{5}$, Stefaan P.O. Werbrouck ${ }^{5}$, Libor Havlíček ${ }^{6}$, Nuria De Diego ${ }^{4}$, Martina Kopečná ${ }^{3}$, Zdeněk Wimmer ${ }^{2,6}$, Pierre Briozzo ${ }^{7}$, Solange Moréra ${ }^{8}$, David Zalabák ${ }^{9}$, Lukáš Spíchal ${ }^{4}$, Miroslav Strnad ${ }^{1}$

${ }^{1}$ Laboratory of Growth Regulators, Institute of Experimental Botany of the Czech Academy of Sciences \& Palacký University, Šlechtitelů 27, CZ-783 71 Olomouc, Czech Republic

2 Department of Chemistry of Natural Compounds, Faculty of Food and Biochemical Technology, University of Chemistry and Technology in Prague, Technická 5, CZ-16628 Prague, Czech Republic

3 Department of Protein Biochemistry and Proteomics, Centre of the Region Hana for Biotechnological and Agricultural Research, Faculty of Science, Palacký University, Šlechtitelu 27, CZ-78371, Olomouc, Czech Republic

${ }^{4}$ Department of Chemical Biology and Genetics, Centre of the Region Haná for Biotechnological and Agricultural Research, Faculty of Science, Palacký University, Šlechtitelů 27, CZ-78371, Olomouc, Czech Republic

${ }^{5}$ Department Plants and Crops, Faculty of Bioscience Engineering, Ghent University, Ghent, Belgium

${ }^{6}$ Isotope Laboratory, Institute of Experimental Botany, The Czech Academy of Sciences, Videňská 1083, 14220 Prague, Czech Republic.

${ }^{7}$ Institut Jean-Pierre Bourgin, INRAE, AgroParisTech, Université Paris-Saclay, Route de Saint-Cyr, F-78026, Versailles, France

${ }^{8}$ Institute for Integrative Biology of the Cell (I2BC), CEA, CNRS, Université Paris-Saclay, 91198, Gif-sur-Yvette, France

${ }^{9}$ Department of Molecular Biology, Centre of the Region Haná for Biotechnological and Agricultural Research, Faculty of Science, Palacký University, Šlechtitelì 27, CZ-78371, Olomouc, Czech Republic

*Corresponding author: Jaroslav Nisler; email:jaroslav.nisler@gmail.com; Tel.: +420 241062485

(C) The Author(s) 2020. Published by Oxford University Press on behalf of the Society for Experimental Biology. All rights reserved. For permissions, please email: journals.permissions@oup.com 


\section{E-mail address for each author:}

Jaroslav Nisler: jaroslav.nisler@gmail.com

David Kopečný: david.kopecny@upol.cz

Zuzana Pěkná: zuzana.pekna@upol.cz

Radka Končitíková: radka.koncitikova@gmail.com

Radoslav Koprna: radoslav.koprna@upol.cz

Nino Murvanidze: nina.murvanidze@gmail.com

Stefaan P.O. Werbrouck: Stefaan.Werbrouck@ugent.be

Libor Havlíček: lihavlic@biomed.cas.cz

Nuria De Diego: nuria.de@upol.cz

Martina Kopečná: martina.kopecna@upol.cz

Zdeněk Wimmer: wimmer@biomed.cas.cz

Pierre Briozzo: pierre.briozzo@inra.fr

Solange Moréra: solange.morera@i2bc.paris-saclay.fr

David Zalabák: davidzalabak@seznam.cz

Lukáš Spíchal: lukas.spichal@upol.cz

Miroslav Strnad: miroslav.strnad@upol.cz

\section{Highlight}

Crystallographic characterization of complexes of cytokinin oxidase/dehydrogenase with its inhibitors has allowed the development of potent inhibitors of cytokinin degradation in plants that can be used in biotechnology and agriculture. 


\begin{abstract}
Increasing crop productivity is our major challenge if we are to meet global needs for food, feed and fuel. Controlling the level of the plant hormones cytokinins is a mean of improving plant productivity. Cytokinin oxidase/dehydrogenase $(\mathrm{CKO} / \mathrm{CKX})$ is a major target in this regard because it degrades cytokinins. Here, we describe the synthesis and biological activities of new CKX inhibitors derived mainly from diphenylurea. They were tested on four CKX isoforms from maize and Arabidopsis, where the best compounds showed $I C_{50}$ values in the $10^{-8} \mathrm{M}$ concentration range. The binding mode of the most efficient inhibitors was characterized from high-resolution crystal complexed structures. Although these compounds do not possess intrinsic cytokinin activity, we have demonstrated their tremendous potential for use in the plant tissue culture industry as well as in agriculture. We have identified a key substance, compound 19, which increases stress resistance and seed yield in Arabidopsis, but also improves the yield of wheat, barley and rapeseed grains under field conditions. Thus our findings reveal that subtle modulation of cytokinin levels via CKX inhibition can positively affect plant growth, development and yield, and underline the fact that CKX inhibitors truly deserve to attract interest in plant biotechnology and agriculture.
\end{abstract}

Keywords: Agriculture, biotechnology, CKX inhibitor, crystal structure, cytokinin, cytokinin oxidase/dehydrogenase, diphenylurea, plant tissue culture, stress, yield. 
Abbreviations: CKX - cytokinin oxidase/dehydrogenase, GM - genetically modified, iP - $N^{6}$ isopentenyladenine, PGR - plant growth regulators, SP - seeds per silique, TFM trifluoromethoxy group, TGW - thousand grain weight. 


\section{INTRODUCTION}

The world population and its need for food, feed and bio-energy fuel are rapidly increasing. Seeds are the major source of the world's food calories. However, recent increases in meat consumption together with the use of grain for biofuel production have placed new pressures on global grain supplies (Edgerton, 2009). One way to meet this challenge is to increase crop productivity on existing farmland. Cytokinins are key plant hormones and numerous improvements in seed yield have been achieved by increasing their content in plants (e.g. Ashikari et al., 2005; Zalewski et al., 2010; Bartrina et al., 2011).

Cytokinins regulate essential plant processes, including cell division, development of shoot, root and reproductive organs, seed fill and senescence (Kieber and Schaller, 2014). They are degraded by cytokinin oxidase/dehydrogenase (abbreviated as CKO or CKX, EC 1.5.99.12, Chatfield and Armstrong, 1986; Hare and Van Staden, 1994), which catalyzes their irreversible oxidative breakdown to adenine/adenosine and the corresponding aldehyde (Whitty and Hall, 1974; Brownlee et al., 1975). Arabidopsis thaliana (At) contains seven $C K X$ genes (Werner et al., 2003). AtCKX2 is the most active and well-studied isoform (Galuszka et al., 2007). Zea mays (Zm) has 13 CKX genes, of which ZmCKX1 plays a crucial role in cytokinin degradation (Houba-Hérin et al., 1999; Morris et al., 1999). Each CKX isoform usually differs in substrate specificity, spatial and temporal expression patterns and subcellular localization (e.g. Šmehilová et al., 2009; Vyroubalová et al., 2009).

Cytokinins became of interest in the search for potential agrochemicals due to their positive effects on tillering, flower and seed setting, delaying of senescence and mitigation of stress consequences (Koprna et al., 2015). Nonetheless, exogenous application of cytokinins has not found a place in agricultural practices, most probably due to the complexity and variability of their effects. However, it has been shown that when levels of endogenous cytokinins are slightly increased throughout certain periods, an improvement in agricultural traits can be achieved. For example, a reduction or loss of function of OsCKX2 in rice (Oryza sativa) led to accumulation of cytokinins in inflorescence meristems resulting in an increased number of reproductive organs (Ashikari et al., 2005). The total grain number per plant was enhanced by $\sim 30 \%$ and the grain size was not affected. The key role of CKX in the formation of inflorescence meristems was also confirmed in Arabidopsis, where double $c k x$ knock-out plants showed 55\% yield increase as a result of higher seed number per silique (Bartrina et al., 2011). Silencing of $H v C K X 1$ expression in barley (Hordeum vulgare) was accompanied by $31-43 \%$ higher grain number. The thousand grain weight (TGW) was approximately $20 \%$ 
higher and total grain yield per plant was 50-65\% higher than those of control plants (Zalewski et al., 2010).

Before genetically modified (GM) plants were engineered, chemical inhibitors of CKX were already known. They were discovered in the 1980s among synthetic cytokinins: diphenylurea, thidiazuron (TDZ), 1-(2-chloropyridin-4-yl)-3-phenylurea (CPPU) and 1-(2,6dichloropyridin-4-yl)-3-phenylurea (DCPPU). They inhibit the degradation of natural cytokinins catalyzed by CKX (Chatfield and Armstrong, 1986; Burch and Horgan, 1989; Kopečný et al., 2010). These ureas are, however, classified as cytokinins because their cytokinin properties clearly outweigh their CKX inhibitory activity. For example, TDZ inhibits CKX only at high micromolar concentrations but exhibits strong cytokinin effects in the low nanomolar range (Nisler et al., 2016). Nowadays, TDZ and CPPU are used as important growth promoters for various horticultural crops, such as kiwi fruit and melons (Arima et al., 1995). Furthermore, TDZ is a component in a large number of agrochemical products used for cotton defoliation in many countries. TDZ also has an irreplaceable role in the plant tissue culture industry for its ability to induce adventitious shoot formation and to promote axillary shoot proliferation (Lu, 1993; Guo et al., 2011).

Anilinopurine derivatives have been shown to be potent CKX inhibitors (Zatloukal et al., 2008) that promote in vitro organogenesis (Aremu et al., 2015) and increase plant stress tolerance toward salinity (Aremu et al., 2014) and cadmium (Gemrotová et al., 2013). A positive effect of F-INCYDE (the name of the most active inhibitor 2-fluoro-6-(3methoxyphenyl)aminopurine) on the heat stress tolerance and grain yield of rice in field conditions was reported by Syngenta in patent applications. Their data obtained in India during the years 2012-2016 demonstrated that F-INCYDE improved the tolerance of rice seedlings to heat and transplanting shock stresses. Treated plants also had a grain yield increase of up to 8.8\% (Camblin and Pingel, 2017; Camblin et al., 2017; Kon et al., 2017). Multi-year analysis for 2015-2016 showed that F-INCYDE increased rice grain yield by up to $6.5 \%$, mainly due to a reduction in the number of empty spikelets and a $2 \%$ increase in TGW. A clear beneficial effect of treatment was observed when the daily maximum temperature was above $36^{\circ} \mathrm{C}$ on at least one day after application (Camblin et al., 2017). These results, together with commercial interest in F-INCYDE, prove that the development of CKX inhibitors offers promise.

Here, we present a comprehensive developmental study and the biological properties of much more potent CKX inhibitors derived from CPPU, DCPPU and diphenylurea. We performed a structure-function study using four CKX enzymes - AtCKX2 from Arabidopsis 
thaliana, and maize ZmCKX1, ZmCKX4a and ZmCKX8. The binding mode of the best two inhibitors with ZmCKX4a and ZmCKX8 isoforms was analyzed by X-ray crystallography. Furthermore, we showed the effects of selected compounds in cytokinin bioassays, and their applications in the field of plant tissue culture. Key compounds were further tested for alleviation of stress responses and for yield enhancement in Arabidopsis. Finally, we evaluated the effect of one compound on yield and yield-forming parameters in rapeseed, barley and wheat in field trials.

\section{MATERIALS AND METHODS}

\section{Cytokinins and Chemicals}

$N^{6}$-benzyladenine (BA), trans-zeatin, CPPU, DCPPU and TDZ were gifts from Olchemim (https://www.olchemim.cz/). 2,6-Dichloro-4-isocyanatopyridine was from Atlantic Research Chemicals (https://atlantic-chemicals.com/). 2-Chloropyridin-4-amine, 1,3-dichloro-5isocyanatobenzene, aniline, 2-(2-aminophenyl)ethan-1-ol, 2-(trifluoromethoxy)aniline, 3-

(trifluoromethoxy)aniline, 4-(trifluoromethoxy)aniline, 2-methoxyaniline, aminophenyl)methanol, 2-aminobenzoic acid, triphenylphosphine $\left(\mathrm{PPh}_{3}\right)$, triethylamine (TEA), hexachloroethane, phthalimide, potassium phthalimide, tert-butyldimethylsilyl chloride, hydrazine, diethyl azodicarboxylate (DIAD), carbonyldiimidazole (CDI) and 2aminoethan-1-ol were purchased from Sigma Aldrich (https://www.sigmaaldrich.com). 2-(2aminophenyl)acetic acid, 1-(2-aminophenyl)ethanol, 3-chloro-5-(trifluoromethoxy)aniline, 3bromo-5-(trifluoromethoxy)aniline, methyl 3-amino-5-chlorobenzoate, 3-chloro-5methoxyaniline, 3-(2,2,2-trifluoroethoxy)phenylamine and 1-isothiocyanato-3(trifluoromethoxy)benzene were from Fluorochem (http://www.fluorochem.co.uk/). Finally, 3-(trifluoromethylthio)aniline was from abcr GmbH (https://www.abcr.de).

\section{General syntheses}

Compounds 1-32 were synthesized by nucleophilic addition of substituted aniline (or aniline) to substituted 4-isocyanatopyridine, isocyanatobenzene or to isothiocyanatobenzene (Goldschmidt and Bardach 1892). If the isocyanate was not commercially available it was synthesized from amine and diphosgene according to Kurita et al. (1976) with minor modifications. Briefly, starting amine $(0.5 \mathrm{mmol})$ was dissolved in dry tetrahydrofuran (THF, $3 \mathrm{~mL})$ and triethylamine $(1.2 \mathrm{mmol})$ was added. This solution was added dropwise to a solution of diphosgene $(0.26 \mathrm{mmol})$ in dry THF $(5 \mathrm{~mL})$ or dichloromethane (DCM, $5 \mathrm{~mL})$ 
at $-20^{\circ} \mathrm{C}$ and then the white suspension was allowed to warm up to laboratory temperature (r.t.) and it was stirred for 30 minutes. If conversion to isocyanate was not complete (monitored by TLC analysis), the solution was warmed up to $50^{\circ} \mathrm{C}$ for another 30 minutes. After cooling to r.t. a white precipitate of triethylamine hydrochloride was filtered off and the remaining solution was evaporated. Crude isocyanates were used, without analysis, directly in further syntheses. This procedure led to synthesis of these isocyanates: 2-chloro-4isocyanatopyridine, 1-isocyanato-3-(trifluoromethoxy)benzene, 1-chloro-3-isocyanato-5(trifluoromethoxy)benzene, 1-bromo-3-isocyanato-5-(trifluoromethoxy)benzene, 1-chloro-3isocyanato-5-methoxybenzene, 1-isocyanato-2-(trifluoromethoxy)benzene, 1-isocyanato-4(trifluoromethoxy)benzene, 1-isocyanato-3-(trifluoromethylsulfanyl)benzene and 1isocyanato-3-(2,2,2-trifluoroethoxy)benzene. The final compounds $\mathbf{1 - 3 2}$ were prepared by stirring a solution containing the isocyanate $(0.5 \mathrm{mmol})$ and the corresponding amine $(0.5$ $\mathrm{mmol}$ ) in THF, DCM or acetone at either laboratory temperature or higher (details are provided further). The formation of urea derivative was monitored using TLC analysis (mobile phase usually chloroform:methanol, 9:1). If the (substituted)-aniline to be coupled with isocyanate contained a free hydroxyl group, this was protected by tertbutylchlorodimethylsilane (TBDMS) according to common protocols prior to the condensation. Then the urea derivative formed was deprotected with 2-propanolic $\mathrm{HCl}$ (Wuts and Greene, 1991). All compounds were characterized by MS-ESI, ${ }^{1} \mathrm{H}$ NMR and melting point analysis. Details of syntheses, purification and analyses are provided in Supplementary material.

\section{General experimental procedures}

Thin-layer chromatography was performed using aluminum sheets with silica gel $\mathrm{F}_{254}$ from Merck. Column chromatography (CC) was performed using Merck silica gel Kieselgel 60 (230-400 mesh). The chromatographic purity was analyzed using HPLC with UV- and PDAdetector (Beckman Gold System, California). The retention time $\left(R_{\mathrm{t}}\right)$ of the compounds synthesized was also scored. Compounds (1 mg) were dissolved in $1 \mathrm{~mL}$ of $10 \%$ methanol and injected $(10 \mu \mathrm{L})$ onto a reverse-phase column (Symmetry C18, $5 \mu \mathrm{m}, 150 \mathrm{~mm} \times 2.1 \mathrm{~mm}$; Waters, Milford, MA, USA) held at $25^{\circ}$ C. Solvent (A) consisted of $15 \mathrm{mM}$ ammonium formate adjusted to $\mathrm{pH}$ 4.0. Solvent (B) was methanol. With a flow-rate of $200 \mu \mathrm{L} / \mathrm{min}$, the following binary gradient was used: $0 \mathrm{~min}, 10 \% \mathrm{~B}$; 0-24 min; linear gradient to $90 \% \mathrm{~B}$; 25$34 \mathrm{~min}$; isocratic elution with $90 \% \mathrm{~B} ; 35-45 \mathrm{~min}$; linear gradient to $10 \% \mathrm{~B}$. Eluting compounds were detected by scanning the UV absorbance of the eluate between 240 and 320 
$\mathrm{nm}$. The effluent was then introduced to a PDA detector. The purity of compounds (\%) was recorded at a compound absorption maximum $\lambda(\max )$. Melting points were determined on a Kofler block and are uncorrected. Mass spectra were determined using a Waters Micromass ZMD mass spectrometer (solution in $\mathrm{MeOH}$, direct inlet, coin voltage $20 \mathrm{~V}$, trace amounts of formic acid or aq. ammonia were used to influence ionization and formation of clusters). The major peaks being reported with intensities quoted as percentage of the base peak. NMR spectra were recorded on a JEOL ECA-500 spectrometer operating at frequency of $500.16 \mathrm{MHz}\left({ }^{1} \mathrm{H}\right) .{ }^{1} \mathrm{H} \mathrm{NMR}$ chemical shifts were referenced to the solvent signals.

\section{CKX inhibition measurements}

The ability of the prepared compounds to inhibit CKXs was determined based on their $I C_{50}$ values in the DCPIP assay (Frébort et al., 2002). For each compound a concentrationdependent curve of CKX residual activity was constructed and $I C_{50}$ determined in GraphPad Prism. The assays were performed at $37^{\circ} \mathrm{C}$ in $100 \mathrm{mM}$ potassium phosphate buffer, $\mathrm{pH} 7.4$ using the substrate $N^{6}$-isopentenyladenine (iP) at a saturating concentration $(45 \mu \mathrm{M}$ for AtCKX2 and ZmCKX4a, $10 \mu \mathrm{M}$ for $\mathrm{ZmCKX1}$ and $12 \mu \mathrm{M}$ for $\mathrm{ZmCKX} 8$ ). The compounds were tested with two replicates and the entire test was repeated at least twice. Pure enzymes were used in the case of $\mathrm{ZmCKX1,} \mathrm{ZmCKX4a} \mathrm{and} \mathrm{ZmCKX} 8$. ZmCKX1 was expressed in the yeast Yarrowia lipolytica and purified according to a published protocol (Kopečný et al., 2005). Escherichia coli BL21 STAR (DE3) cells carrying pTYB12-ZmCKX4a and ZmCKX8 plasmids were grown at $18^{\circ} \mathrm{C}$ overnight and enzymes were purified as published (Zalabák et al., 2014). In the case of AtCKX2, the enzyme produced in growth media from Saccharomyces cerevisiae was used (Frébortová et al., 2007).

\section{Crystallization and structure refinement of $\mathrm{ZmCKX4a}$ and $\mathrm{ZmCKX8}$ complexes}

ZmCKX4a (15 mg/mL, $50 \mathrm{mM}$ Tris-HCl, $\mathrm{pH}$ 8.0) was co-crystallized with $2 \mathrm{mM}$ compound 19 or 20 in drops containing $100 \mathrm{mM}$ HEPES buffer $\mathrm{pH} 7.5$ and 50\% 2-methyl-2,4pentanediol. Crystals were immediately plunged into liquid nitrogen. ZmCKX8 $(17 \mathrm{mg} / \mathrm{mL}$, $50 \mathrm{mM}$ Tris-HCl, $\mathrm{pH}$ 8.0) was crystallized in $100 \mathrm{mM}$ HEPES buffer $\mathrm{pH} 7.5,15 \%$ polyethylene glycol and $15 \%$ isopropanol. Crystals were soaked with $4 \mathrm{mM}$ compound $\mathbf{2 0}$ for 40 seconds and then cryoprotected using $15 \%$ glycerol. Diffraction data were collected at 100 $\mathrm{K}$ on the Proxima 1 beamline at the SOLEIL synchrotron (Saint-Aubin, France) at $1.95 \AA$ resolution. Intensities were integrated using the XDS program (Kabsch 2010). Data quality was assessed using the correlation coefficient $C C_{1 / 2}$ (Karplus and Diederichs 2012). The 
crystal structure of ZmCKX8 was determined by performing molecular replacement with Phaser (Storoni et al., 2004) using a monomer of ZmCKX4a (PDB ID 4O95) as a search model (Kopečný et al., 2016). Model refinement was achieved with BUSTER-TNT (Bricogne et al., 2011) and electron density maps were evaluated using COOT (Emsley and Cowtan, 2004). Structure quality was validated using MolProbity (Chen et al., 2010). Molecular graphics images (Fig. 2B-2E) were generated using PyMOL software.

\section{Cytokinin bioassays}

The Arabidopsis ARR5::GUS reporter gene assay was generally done as described previously (Romanov et al., 2002) and details are in Nisler et al. (2016). The CRE1/AHK4 cytokinin receptor activation assay was done as described by Spíchal et al. (2004). The wheat leaf senescence assay was performed as described by Holub et al. (1998).

\section{Quantitative real-time PCR}

Arabidopsis thaliana was grown on agar for 1 week and subsequently, plants were treated with water (control), $5 \mu \mathrm{M} N^{6}$-benzyladenine (BA, positive control), $5 \mu \mathrm{M}$ and $0.1 \mu \mathrm{M}$ inhibitor 19. RNA was collected at 1, 3, 5 and 24 hours after the spraying. The total RNA was isolated using TRIzol reagent (100 $\mathrm{mg}$ sample per $1 \mathrm{ml}$ reagent). Phase separation was achieved by the addition of chloroform $(0.2 \mathrm{ml})$ and upon centrifugation at $12000 \mathrm{x} \mathrm{g}$ for 15 minutes at $4^{\circ} \mathrm{C}$, the colorless upper aqueous phase was collected. RNA was further precipitated by the addition of $0.5 \mathrm{ml}$ 2-propanol for 10 minutes. The RNA precipitate was centrifuged at $12000 \mathrm{x} \mathrm{g}$ for 10 minutes at $4^{\circ} \mathrm{C}$ to remove the supernatant. The RNA pellet was washed using $1 \mathrm{ml}$ of $75 \%$ ethanol, vortexed and centrifuged again at $7500 \mathrm{x} \mathrm{g}$ for 5 minutes at $4{ }^{\circ} \mathrm{C}$. The RNA pellet was air-dried on ice for 5 minutes, resuspended in water and treated twice with a Turbo DNase-free kit (Ambion). First-strand cDNA was synthesized by SuperScript III reverse transcriptase and oligo(dT) primers (Thermo Fisher Scientific). The RNA was transcribed from three biological replicates (each replicate represents 15 plantlets) and qPCR reactions were performed in quadruplicate on a QuantStudio 5 Real-Time PCR System using Luna universal probe qPCR master mix (New England Biolabs), both primers at $400 \mathrm{nM}$ concentration and $200 \mathrm{nM}$ dual-labeled TaqMan probe (FAM/TAM or FAM/MGBNFQ). Primers and TaqMan probes were designed using Primer Express 3.0 software (Life Technologies) and are shown in Table S1. Cycle threshold values were normalized for AtEF $1 \alpha$ and AtACT8 genes and amplification efficiency. Expression values were obtained from four independent replicates, each consisting of 15 plants. Expression values were 
determined and statistically evaluated using the DataAssist v3.0 Software package (Life Technologies). Before performing a t-test, data groups were verified by an F-test whether they possess the same variance. Gene names, dual probes and primer pairs used for qPCR are given in Table $\mathrm{S} 1$.

\section{Shoot regeneration on tobacco leaf disks and poplar explants}

Tobacco (Nicotiana tabacum) leaf discs (ac. $0.5 \mathrm{~cm}$ ) were placed in Petri-dishes with $10 \mathrm{ml}$ Murashige and Skoog medium, including $30 \mathrm{~g} / \mathrm{L}$ sucrose and $7 \mathrm{~g} / \mathrm{L}$ plant agar (pH 5.8). After autoclaving, this medium was supplemented with $0,0.01,0.1$ or $1 \mu \mathrm{M}$ compound 19 or 21 combined with $0,0.01,0.1$ or $1 \mu \mathrm{M}$ iP. For each hormone, 3 replicates each of 5 leaf discs were used. The experiment was evaluated after 3 weeks and repeated 3 times.

Shoot regeneration in poplar (Populus $\times$ canadensis 'Robusta') involved two steps. In the first phase, callus induction was initiated for 2 weeks on a callus induction medium consisting of Murashige and Skoog salts and vitamins supplemented with $30 \mathrm{~g} / \mathrm{L}$ sucrose, $7 \mathrm{~g} / \mathrm{L}$ agar and $1 \mathrm{mg} / \mathrm{L}$ 2,4-dichlorophenoxyacetic acid. Afterwards, the explants were transferred to a shoot induction medium consisting of the same basal medium, but containing a combination of 0 or $1 \mu \mathrm{M}$ iP with 0 or $1 \mu \mathrm{M}$ compound 19 or $\mathbf{2 0}$. Leaf disks $\left(0.5-1 \mathrm{~cm}^{2}\right)$ were punched out from in vitro plantlets. Fifteen explants in each of three replicates per treatment were used in the experiment. The experiment was evaluated after 4 weeks.

\section{Alleviation of stress consequences in Arabidopsis seedlings}

The assay was performed as described to the detail by Ugena et al. (2018). Arabidopsis thaliana (ecotype Col-0) seeds were germinated on full MS medium for three days without any treatment. Afterwards they were transferred to the same medium containing $10 \mathrm{nM} 19$ in the absence or presence of the abiotic stress factor. DMSO $(0.1 \%)$ was used as a solvent control in all variants. The dynamics of rosette growth and the relative growth rate were evaluated by recording the green area by RGB imaging twice a day during the 6 days after the seedling transfer in the PlantScreen ${ }^{\mathrm{TM}}$ XYZ system (Photon Systems Instruments, Brno, Czechia).

\section{Effects of compound 19 on phenotype and seed yield of $A$. thaliana}

Arabidopsis thaliana (ecotype Col-0) was grown in a growth chamber on soil at $24^{\circ} \mathrm{C}$ under long-day conditions (16 h light/8 h dark), a light intensity of $100 \mu \mathrm{mol} / \mathrm{m}^{2} \mathrm{~s}$, and $65 \%$ humidity. Compound 19 was dissolved in water (with $0.1 \%$ DMSO and $0.01 \%$ silwet) and 
sprayed on plants 12 days after transfer from $4{ }^{\circ} \mathrm{C}$ to the growth chamber. In the first experiment, 25 plants were grown for each treatment (control, $0.1,1$, and $10 \mu \mathrm{M} 19$ ) and for all sets of plants, the number of siliques per plant and total grain yield were determined. The SP parameter was evaluated from 10 randomly selected plants from each treatment and from 6 siliques of each plant. The weight of 100 seeds was determined 3 times for each treatment from the combined sample. In a second experiment, we used the same approach with 18 plants. In addition, their rosette leaf size was determined on 25 day of growth in Adobe Photoshop Elements 9, where rosette area was selected manually using the magic wand tool.

\section{Field trials}

Field experiments were done with spring barley (Hordeum vulgare), winter wheat (Triticum aestivum) and winter rapeseed (Brassica napus) according to the criteria for Good Agricultural Practices (six randomized plots of $10 \mathrm{~m}^{2}$ were used for one variant). The plot was treated solely with compound 19.

\section{RESULTS AND DISCUSSION}

\section{Design and chemistry of novel CKX inhibitors}

In previous studies (Kopečný et al., 2010, Nisler et al., 2016), we analyzed several CPPU and TDZ derivatives and their inhibitory strength towards CKXs. Our results shed light on the reactive loci of the urea compounds essential for their binding at the active site of CKX and allowed the targeted design of new compounds. Insertion of 2-hydroxyethyl at the orthoposition of the TDZ phenyl ring (the name of the compound was abbreviated to 2HE-TDZ (Fig. 1A)) enhanced the inhibitory strength of the ligand (Nisler et al., 2016). We therefore synthesized the corresponding derivatives of CPPU and DCPPU (compounds 1 and 4, Fig. 1B and Table 1). Moreover, we found that 1-(3,5-dichlorophenyl)-3-phenylurea (6) exhibits slightly better inhibitory potency than DCPPU. This diphenylurea was therefore selected for a larger screening study, in which its empty phenyl ring received one or two carbon-containing substituents in the ortho-position to evaluate their effect on CKX inhibition (compounds 6-15, Fig. 1C and Table 1).

Another strong stimulus for further development was the fact that compound 3TFMTDZ (Fig. 1A) binds at the active site of $\mathrm{ZmCKX} 4 \mathrm{a}$ in the opposite orientation to that of 2HE-TDZ (Nisler et al., 2016). The compound 1-(2-(2-hydroxyethyl)phenyl)-3-(3- 
(trifluoromethoxy)phenyl)urea (19, 3TFM-2HE, Fig. 1A) was therefore synthesized and analyzed (Table 2 and 3). Among the four compounds 16-19 (Fig. 1D), compound 19 exhibited the highest CKX inhibitory potency, comparable to that of $\mathbf{1 2}$. It became obvious that CKX isoforms had space to accommodate not only the trifluoromethoxy group (TFM) but also two chlorine atoms, as found in the structure of 12. Thus compounds 20,21 and 22 were synthesized (Fig. 1D and Table 2). Compounds 23-31 (Fig. 1E and Table 2) were produced to explore the structure-activity relationships of compounds modified on the ring bearing the 3TFM group. The thiourea derivative 32 was designed analogously to the active urea 19. Finally, 2 and 5 were prepared to analyze the effect of a 3-methoxyphenyl group, which is present in the F-INCYDE structure.

Compounds 1-32 were prepared according to common protocols for the synthesis of diphenylurea derivatives (Goldschmidt and Bardach, 1892). Many derivatives of diphenylurea, CPPU and DCPPU have been previously prepared (Bruce and Zwar, 1966; Takahashi et al., 1978; Okamoto et al., 1981), but only Kopečný et al. (2010) analyzed their CKX inhibitory activity.

\section{Inhibition of AtCKX2 and ZmCKX1}

AtCKX2 and ZmCKX1 are among the most active isoforms in their species (Galuszka et al., 2007; Zalabák et al., 2014). It is known that ZmCKX1 is expressed in maize roots, tassels and kernel (Vyroubalová et al., 2009, Zalabák et al., 2014). Expression from the AtCKX2 gene was detected in the shoot apex, in stipules, and occasionally in the most apical parts of inflorescence stems. ZmCKX1 is an extracellular and glycosylated isoform (Kopečný et al., 2005; 2006). AtCKX2 may also be an extracellular isoform (Werner et al., 2003). Recently, a homology model of AtCKX2 revealed that the amino acid composition of its active site is almost identical to that of ZmCKX1 (Nisler et al., 2016).

The attachment of a 2-hydroxyethyl group to the ortho position of the phenyl ring of CPPU and DCPPU led to improvement in the CKX inhibitory strength of both molecules (compounds 1 and 4). The attachment of a methoxy group to the meta position had the opposite effect (compounds 2 and 5). Interestingly, a diphenylurea derivative 3,5DCl-Ph-U (6) displayed better inhibitory activity than the pyridyl-phenylurea derivative DCPPU. This means that the presence of endo-cyclic nitrogen is not essential for CKX inhibition. This result was also confirmed in the case of ligand 12, which displayed approximately 7 times lower $I C_{50}$ than 4. Among all other substituents tested on the 3,5DCl-Ph-U backbone, only 
hydroxymethyl (8) and 2-hydroxyethyl (12) groups increased the compound's inhibitory activity. An overview of the $I C_{50}$ values is given in Table 1.

Compounds 16-22 are 1-phenyl-3-(3-trifluoromethoxyphenyl)urea (3TFM-Ph-U) derivatives (Fig. 1D, Table 2). The compounds 16 and 19 exhibit very similar $I C_{50}$ values to those of compounds 8 and 12, which contain a 3,5-dichlorophenyl ring (Fig. 1C), respectively. This demonstrates that the TFM group has a comparable effect on $I C_{50}$ to that of two chlorines. If the compound contains, on one phenyl ring, a combination of a TFM group with chlorine (20), bromine (21) or 2-hydroxyethylamine (22), the $I C_{50}$ value decreases to $10^{-8} \mathrm{M}$. These compounds are the strongest inhibitors of AtCKX2 and ZmCKX1 of all the derivatives developed so far (Table 2 and 3 ).

Compounds 23-32 are 1-(2-(2-hydroxyethyl)phenyl)-3-phenylurea (Ph-2HE-U) derivatives (Fig. 1E, Table 2) with modifications on the TFM-bearing ring. It is very interesting to compare the inhibitory activity of compounds $\mathbf{2 0}$ and $\mathbf{2 4}$, the latter being distinguished by missing three fluorine atoms from the methoxy group. This inhibitor showed an almost 8-fold loss of inhibitory activity compared to $\mathbf{2 0}$. Compounds $\mathbf{2 8}$ and 29, having the TFM group in, respectively, ortho and para-positions, exhibit much weaker inhibitory potency than compound 19. Conversely, the exchange of the TFM group in the structure of $\mathbf{1 9}$ for a trifluoromethylsulfanyl group (compound 30) results in a lower $I C_{50}$, as shown in Table 2. Finally, results obtained with 32 (the thiourea analogue of 19) revealed that this modification is not a promising way to produce efficient CKX inhibitors.

In summary, most of the compounds studied displayed the same structure-inhibitory relationships towards both enzymes. However, some differences can be observed. ZmCKX1 is somewhat more sensitive to inhibition and less selective than AtCKX2. For example, compounds 2, 5, 9, 11, 14 and 17 are better inhibitors of ZmCKX1 (Table 1). Such information could be used to develop CKX inhibitors with increased selectivity with respect to monocotyledonous and dicotyledonous plant species.

\section{Inhibition of $\mathrm{ZmCKX8}$}

ZmCKX8 transcripts are abundant in maize roots and stem (Vyroubalová et al., 2009; Zalabák et al., 2014). The ZmCKX8 binding pocket is similar to that of $\mathrm{ZmCKX1}$. The presence of a non-conserved glutamate (E372 in ZmCKX8 and E381 in ZmCKX1) favors binding of 
smaller substrates such as cytokinin bases. Despite this similarity, ZmCKX8 showed markedly different sensitivity towards each inhibitor.

A significant difference compared to ZmCKX1 is the stronger binding of CPPU and DCPPU to $\mathrm{ZmCKX8}$ and the fact that neither an additional 2-(2-hydroxyethyl) nor 3-methoxy groups improved the $I C_{50}$ values of these derivatives (Table 1). The substitution of the pyridine ring with phenyl (DCPPU versus 6) did not improve the $I C_{50}$ values either. Addition of a hydroxymethyl group (8) or 2-hydroxyethyl group (12) on compound 6 had a negative or no effect respectively. Only further substitution of $\mathbf{1 9}$ with chlorine or bromine led to any significant improvement as observed for compounds $\mathbf{2 0}$ and 21, which exhibited $I C_{50}$ values in the $10^{-8} \mathrm{M}$ concentration range (Table 2).

\section{Inhibition of $\mathrm{ZmCKX4a}$}

ZmCKX4a represents the second group of CKX isoforms that differ in the residue located at the entrance to the active site. ZmCKX4a has a small nonpolar residue, A373, which clearly allows the binding of bulkier substrates, such as cytokinin glucosides or monophosphates (Kopečný et al., 2016). For this reason, selected inhibitors were evaluated against CKX isoforms from both groups. ZmCKX4a is expressed in immature tassels. The ability of the compounds studied to inhibit $\mathrm{ZmCKX} 4 \mathrm{a}$ was generally weaker compared to other isoforms. However, the inhibition pattern was similar to that of ZmCKX8. For example, addition of a 2hydroxyethyl group did not strengthen the inhibitory activity, as can be seen from a comparison of compound 1 versus CPPU, compound 4 versus DCPPU, and compound 6 versus 12. On the other hand, substitution of the pyridine ring by phenyl (DCPPU versus 6 and 4 versus 12) improved $I C_{50}$ by about $50 \%$ (Table 1). Compound 19 showed an average $I C_{50}$ value and only the presence of additional substituent resulted in a marked increase in inhibitory strength, as can be seen for compounds $\mathbf{2 0}$ and $\mathbf{2 1}$. No other compounds showed improvement (Table 2).

\section{Summary of CKX inhibition}

We compared the inhibitory potency of key derivatives identified in this study with those of the best known CKX inhibitors (Fig. 2A and Table 3). It is obvious that known compounds exhibited $I C_{50}$ values spanning high nanomolar and low micromolar concentrations, with FINCYDE being the best. However, compound 19 studied here exhibited 10-fold lower $I C_{50}$ values, and further improvement was achieved by the introduction of another halogen atom. 
This development led to compounds $\mathbf{2 0}$ and $\mathbf{2 1}$, which are the best inhibitors of all substances studied to date, and which all inhibit three CKXs at $10^{-8} \mathrm{M}$ concentrations.

\section{Mode of binding of inhibitors 19 and 20 at the active site of CKX}

The binding mode of compounds $\mathbf{1 9}$ and $\mathbf{2 0}$ was characterized using three high-resolution crystal structures of $\mathrm{ZmCKX} 4 \mathrm{a}$ and $\mathrm{ZmCKX8}$ complexes (Table S2). While the structure of ZmCKX4a itself, as well as in complex with CPPU and TDZ-derived inhibitors, has been published (Kopečný et al., 2016; Nisler et al., 2016), that of ZmCKX8 has never been described. The structure of ZmCKX8 is very similar to that of ZmCKX1 and ZmCKX4a with RMSD values of $1.13 \AA$ (471 C $\alpha$ atoms) and $0.92 \AA$ (436 C $\alpha$ atoms), respectively (Fig. S1). ZmCKX8 exhibits the typical two-domain topology of the FAD-binding domain (residues 32-242 and 487-530) and the substrate-binding domain (residues 243-486). In general, the structures comprise 19 helices and 17 strands like in the case of ZmCKX1 and as deduced by DSSP (Kabsch and Sander, 1983). A significant difference is the presence of two helices ( $\alpha 10$ and $\alpha 11)$ above the entrance to the substrate channel, which is similar to the ZmCKX1 structure. On the contrary, the equivalent region is highly disordered in $\mathrm{ZmCKX} 4$. Both $\mathrm{ZmCKX} 1$ and $\mathrm{ZmCKX} 8$ are more ordered at the $\mathrm{N}$-terminus and carry additional $\alpha$-helix.

The crystal structure complexes indicated that inhibitors bind to the CKX active site similarly to cytokinin substrates (Fig. 2C). Both ligands interact with one oxygen atom of the catalytic aspartate (D169/170/167 in ZmCKX1/ZmCKX4a/ZmCKX8) via their nitrogen atoms. These urea nitrogen atoms establish a bidentate hydrogen bond with distances of between $2.9 \AA$ and $3.1 \AA$. Both inhibitors adopt a planar conformation parallel to the plane of the isoalloxazine ring of the FAD cofactor allowing favorable "parallel-displaced" $\Pi-\Pi$ electrostatic interactions. The oxygen atom of the 2-hydroxyethyl side chain replaces a water molecule observed in cytokinin bound structures and it makes H-bonds with the hydroxyl group of Tyr425 and the oxygen atom of Asp170 in ZmCKX4a (Tyr422 and Asp167 in ZmCKX8) (Fig. 2B-E). The 3-TFM-phenyl ring of ligand 19 in ZmCKX4a points toward the hydrophobic pocket composed of the side chains of Trp389, Trp383, Phe57, Leu377 and His387 (Fig. 2B). The 3-chloro-5-TFM-phenyl ring of ligand 20 overlaps with the 3-TFMphenyl ring of ligand 19 when comparing the $\mathrm{ZmCKX} 4 \mathrm{a}$ and $\mathrm{ZmCKX8}$ structures (Fig. 2D and $2 \mathbf{E}$ ). The chlorine atom points outside the binding cavity. Neither the chlorine nor the 3TFM group makes any direct hydrogen bond with neighboring residues. 
Activation of the cytokinin primary response reporter and interaction with cytokinin perception

Since the diphenylurea derivatives display cytokinin activity and binding features common to purine-based cytokinins (Bruce and Zwar, 1966), the most promising compounds from this work were tested for cytokinin responses in planta. We used transgenic Arabidopsis plants harboring the ARR5:GUS reporter gene (D'Agostino et al., 2000). ARR5 is a primary response gene with a cytokinin-dependent promoter, which integrates the responses of cytokinin signaling pathways, including those linked to the cytokinin receptors AHK2, AHK3 and AHK4. The activity of the compounds was compared with that of $1 \mu \mathrm{M} N^{6}$-benzyladenine (a positive control, Fig. 1F).

Compounds CPPU and DCPPU both strongly activated the expression of ARR5. Compounds 4 and 6 reached $\sim 30 \%$ of the DCPPU activity, which means that the 2-(2-hydroxyethyl) group in $\mathbf{6}$ and substitution of a nitrogen atom with a carbon atom in $\mathbf{4}$ both decrease the ability to activate $A R R 5$ expression. All other compounds tested showed only limited ability to trigger ARR5 expression (mostly under $20 \%$ of $1 \mu \mathrm{M} N^{6}$-benzyladenine activity). Compounds were further tested for their ability to directly activate the AHK4 receptor. All compounds tested - 1-6, 10-14, 19, 20 and 21 - were totally inactive towards this receptor (Fig. S2). Thus it can be assumed that, the observed negligible activity of some derivatives in the ARR5 assay is not a result of their intrinsic cytokinin activity, but that the activity can instead be attributed to an increased level of endogenous cytokinins caused by inhibition of AtCKXs. Arabidopsis seedlings were grown in the presence of the tested compounds for 16 hours, giving enough time for endogenous hormone levels to be altered. It is also well known that the rapid turnover (within hours) of cytokinins is controlled by CKXs (Terrine and Laloue, 1980; Redig et al., 1996; Schmülling et al., 2003).

\section{The effect of compound 19 on $C K X$ and $A R R$ gene expression in Arabidopsis}

The conclusion suggested above is consistent with our results obtained in gene expression analysis of the cytokinin primary response genes belonging to the type-A $A R R$ gene family, rapidly elevated by cytokinins (D'Agostino et al., 2000). Compound 19 downregulated ARR5 during the first 5 hours after treatment but a two-fold upregulation of ARR5 was observed already 24 hours after the treatment. The other $A R R$ genes analyzed (ARR7, ARR 9 and ARR16) behaved similarly, their expression was either not significantly altered or it was downregulated during the first 5 hours after treatment, but all of them became gently 
upregulated 24 hours after treatment (Fig. S3A). The course of ARRs expression after administration of cytokinin BA was completely different. All ARRs analyzed were significantly upregulated in all time points and, to a higher extent when compared to the effect of 19. The expression of the type-A $A R R$ and cytokinin levels are undoubtedly correlated. (e.g. Kiba et al., 2019). Our results thus indicate that during the first hours after application of 19 the level of active cytokinins is rather decreased and turns steadily back and even higher after that. Such an increase of active cytokinins already after 1 day upon treatment is most likely responsible for the biological activity of the CKX inhibitors.

Regarding the expression of the AtCKX gene family, both treatments (BA and 19) upregulated most of the analyzed AtCKXs in all time points and, the upregulation intensified over time. This response was generally stronger to BA application than to treatment with 19 (Fig. S3B). These results indicate that compound 19 disrupts the homeostasis of cytokinin metabolism less than BA and even though $C K X$ genes become upregulated, the compound 19, with a slight delay, stimulates the cytokinin signaling pathway.

\section{The effect of selected compounds on retention of chlorophyll in wheat leaves}

Cytokinins are known to delay leaf senescence (Gan and Amasino, 1995; 1997) including chlorophyll degradation as measured in a wheat leaf senescence assay. Leaves treated with TDZ and $t Z$, the two strongest cytokinins, retain approximately $80 \%$ of their chlorophyll after five days in the dark. DCPPU can only retain of about $40 \%$ and CPPU is almost inactive in this assay. Among the new urea compounds, those behaving as weak CKX inhibitors were inactive or retained only up to $10 \%$ of chlorophyll (compared to the DMSO control), while the strongest CKX inhibitors $(4,12,19,20,21)$ preserved $\sim 20 \%$ more than the DMSO control (Fig. S4). This slight anti-senescence activity is significantly lower than the activity of classic cytokinins and again is likely to be due to inhibition of CKX and maintenance of endogenous cytokinins in the leaves.

\section{Shoot regeneration on tobacco leaf disks}

Tobacco is very responsive to the shoot-inducing effects of cytokinins. After three weeks of incubating with tobacco leaf disks, it was clear that iP alone was able to induce adventitious shoots only when $0.1 \mu \mathrm{M}$ or higher concentrations were used. Compounds $\mathbf{1 9}$ and $\mathbf{2 1}$ failed to produce shoots, at any concentration, when applied alone (Fig. 1G and Table 4). This demonstrates that these compounds do not exhibit shoot-forming (cytokinin) activity in 
tobacco explants. However, an interesting synergistic effect of both iP and the inhibitor was observed. A minimal level of $0.01 \mu \mathrm{M}$ compound 21 was sufficient to boost the shoot induction ability of $0.01 \mu \mathrm{M}$ iP. For compound 19, $0.1 \mu \mathrm{M}$ was needed to show this effect. Also when higher concentrations of iP were combined with inhibitors, their stimulatory effect could be observed. Cytokinin iP has a double bond in its chemical structure which makes it vulnerable to the action of cytokinin oxidases (Kamínek, 1992). These findings demonstrate that the compounds 19 and 21 block the breakdown of iP in in vitro plantlets, and enhance its morphogenetic activity. Compound 21 performed better than compound 19 in this bioassay, which correlates well with their $I C_{50} \mathrm{CKX}$ values (Table 2).

\section{Indirect shoot regeneration on poplar leaf explants}

In the widely planted tree Canadian poplar, induction of adventitious shoots is uncommon (Kutsokon et al., 2013). Compounds 19 and 21 were tested alone or in combination with iP for their ability to enhance the effect of a suboptimal concentration of iP on de novo shoot formation on leaf explants. When applied alone, neither $1 \mu \mathrm{M}$ iP nor compounds $\mathbf{1 9}$ and 21 induced shoots after 4 weeks of incubation. On the other hand, de novo shoot formation occurred when iP was combined with 19 or 21 (Fig. 1I and S5). The highest average number of regenerated shoots per explant (1.3) was observed for $1 \mu \mathrm{M}$ iP $+1 \mu \mathrm{M} \mathbf{2 1}$, followed by the combination of iP with 19 (0.3 of regenerated shoots per explant). The results demonstrate again that compounds $\mathbf{1 9}$ and $\mathbf{2 1}$ do not show cytokinin activity but do protect iP against degradation in planta. This result has never previously been shown in Populus $x$ canadensis and certainly not for iP, which is generally considered to be a rather weak cytokinin.

\section{Alleviation of stress consequences in Arabidopsis seedlings}

Compound 19 was tested for its ability to alleviate the effects of abiotic stress on Arabidopsis seedlings, represented by application of $100 \mathrm{mM} \mathrm{NaCl}$ as salinity stress or $100 \mathrm{mM}$ mannitol as osmotic stress. The abiotic stress conditions caused severe penalties in terms of shoot biomass formation and relative growth rate. Salt and osmotic stress reduced the shoot green area by $63 \%$ and $42 \%$ respectively, whereas treating the seedlings with compound 19 alleviated the penalty by almost $20 \%$. The same trend was observed for average relative growth rate, which was lowered to $51 \%$ and $62 \%$ by the stressors, whereas the presence of 19 reduced this negative effect by $\sim 11 \%$ (Fig. 1 H and Table S3). The growth of Arabidopsis seedlings under optimal conditions was not affected by $10 \mathrm{nM}$ compound 19 during the experiment. 


\section{Effect on phenotype and seed yield of $A$. thaliana}

Arabidopsis seedlings were sprayed once with compound 19 at the stage of four true leaves (up to 14 days after planting). Treated plants produced a higher number of seeds per silique (SP) without affecting the total number of siliques per plant. The control plants had $25.6 \pm 6.1$ SP, while plants treated with $0.1,1.0$ and $10 \mu \mathrm{M}$ compound 19 had $36.0 \pm 6.7,33.2 \pm 7.3$ and $32.4 \pm 6.1 \mathrm{SP}$ (an increase by $41 \%, 30 \%$ and $27 \%$ ) respectively. The results were significantly different at $\mathrm{P}=0.03$. Total grain yield was increased by $21 \%$ and $17 \%$ after application of, respectively, $0.1 \mu \mathrm{M}$ and $1.0 \mu \mathrm{M}$ 19. The highest concentration, $10 \mu \mathrm{M}$, was not effective. The weight of 100 seeds of treated plants was lowered by 5-8\% compared with non-treated plants. Van Daele et al. (2012) reported a negative correlation between seed number produced per plant and seed size in many Arabidopsis mutants altering seed production.

In a second independent experiment, plants treated with $0.1,1.0$ and $10 \mu \mathrm{M}$ compound 19 displayed an increase in SP of $18 \%, 21 \%$ and $14 \%$, respectively $(\mathrm{P}=0.05)$. Again, the weight of 100 seeds of treated plants was lower by 4-7\%; however, total grain yield was significantly higher (at $\mathrm{P}=0.05$ ) by $19 \%$ and $15 \%$ after, respectively, $0.1 \mu \mathrm{M}$ and $1.0 \mu \mathrm{M}$ applications. The seed yield of the plants treated with $10 \mu \mathrm{M} 19$ was $6 \%$ lower, indicating that this concentration, as in the first experiment, is indeed too high. The treated plants had up to $38 \%$ (0.1 $\mu \mathrm{M}$ 19) larger leaf rosettes than control plants 25 days after sowing (Fig. S6). This finding indicates higher growth rate in the treated plants. Furthermore, we observed that siliques of controls ripened earlier than siliques of treated plants (Figures S7a and S7b). The lifespan of all treated plants was extended by approximately 10 days compared to control plants. This is consistent with the observation of Gan and Amasino (1995), who demonstrated that endogenously produced cytokinins can delay senescence in transgenic tobacco plants. Longer photosynthetically-active lifetime could also contribute to a higher yield, as the plants had more time for seed filling.

\section{Discussion on cytokinin activity versus CKX inhibition}

Currently, three types of compounds are available that induce cytokinin effects in plants. These substances have different relationships to the CKX enzyme. The published data, together with results in this article, indicate that, for this reason, there are at least 3 possible scenarios for their action in plants. 
1) Natural cytokinins (cis/trans-zeatin, iP, $N^{6}$-benzyladenine or meta-topolin) exhibit strong cytokinin effects, but they are also excellent CKX substrates. They are usually applied on/to plants in a single dose at one time point. Thus, it is possible that the concentration of cytokinin at the time of administration is too high, but after a few days it is too low, depending on the rate of inactivation and degradation. This may initially cause hormonal imbalances and stress, while on the other hand having no long-term positive effects. For these reasons, the results of field experiments with cytokinins are very variable and difficult to reproduce, contributing to the fact that natural cytokinins have not found an assured role among commercialized plant growth regulators (PGR) (reviewed by Koprna et al., 2015).

2) Some strong synthetic cytokinins (TDZ, CPPU) have little ability to inhibit CKXs. Their cytokinin effect may last for a longer period of time, because of their higher resistance to CKX degradation. However, their use can overdose plants with a cytokinin signal that results from a combination of their exogenous application and increased endogenous cytokinin levels due to CKX inhibition. Again, this can cause negative and/or side effects. For example, in some plant species it leads to an overproduction of ethylene, which is used for defoliation of cotton in the case of TDZ (Suttle, 1985, 1986). Except for this application, synthetic cytokinins are commercially used only in the horticultural and floricultural sectors (reviewed by Nisler, 2018).

3) Conversely, there are strong CKX inhibitors with no or very limited cytokinin activity. FINCYDE (according to Zatloukal et al., 2008) and key compounds from this work (19, 20 and 21) belong to this group, as indicated by the results presented here. These compounds can moderately, and over the long-term, increase the level of endogenous cytokinins, which seems to be a considerable advantage over their exogenous application (Gemrotová et al., 2013; Kon et al., 2017; results from this work).

\section{Field trials with spring barley, winter wheat and winter oilseed rape}

Finally, we investigated the effect of compound $\mathbf{1 9}$ on the yield of important crop species and on some of their yield-forming parameters in field trials (according to Good Agricultural Practices criteria).

Spring barley. In 2016, barley seeds were primed with compound 19 at 10 or $50 \mu \mathrm{M}$ concentrations. The resulting plants had higher seed yields by $3.0 \%$ and $0.7 \%$, compared to controls (Table 5), and TGW for the $10 \mu \mathrm{M}$ treatment was $1.8 \%$ higher than that of control plants. Phenotype analysis further showed that the higher yield (for $10 \mu \mathrm{M}$ treatment) could 
be due to a greater number of strong and medium tillers, of which the treated plants had $9.8 \%$ more. In 2017, the effect of foliar application of a $5 \mu \mathrm{M}$ concentration of 19 at two different growth stages was investigated. Treatments at growth phases BBCH 21-23 and BBCH 51 increased seed yield by $6.3 \%$ and $6.4 \%$ respectively, compared to untreated plants.

Winter wheat. In 2017, wheat seeds were primed with $50 \mu \mathrm{M}$ compound 19. The mature treated plants had a $4.0 \%$ higher seed yield and $28.0 \%$ more strong and medium tillers than the control plants (Table 5). The same experiment, repeated in 2018, resulted in a $6.6 \%$ increase in seed yield; however, the number of strong and medium tillers was decreased by 4.7\%. In 2017, the foliar application of $5 \mu \mathrm{M} 19$ at BBCH 25 and at BBCH 51 growth stage resulted in seed yields greater by $5.9 \%$ and $5.0 \%$ respectively, compared to control plants.

Winter rapeseed. In 2017, the foliar application of a $5 \mu \mathrm{M}$ solution of $\mathbf{1 9}$ at BBCH 30 and BBCH 33-35 resulted in a higher seed yield, by $5.7 \%$ and $7.5 \%$ respectively, as compared to controls (Table 5). In addition, the seeds of the treated plants were slightly heavier; TGW of controls was $5.51 \mathrm{~g}$, while for treated plants it was $5.70 \mathrm{~g}$ (BBCH 30) and $5.79 \mathrm{~g}$ (BBCH 3335). This phenomenon contributed to an increase in the overall seed yield.

In field trials, compound 19 was applied at $0.51 \mathrm{~g} / \mathrm{ha}(300 \mathrm{~L}$ of $5 \mu \mathrm{M}$ solution per hectare). This is a very small amount when compared to typical doses of other commercially-applied agrochemicals that increase cereal yield. The PGR thus used to date can be divided into two groups. 1) Chemicals that block gibberellin biosynthesis and thus reduce stem growth and lodging. If the seed yield is higher, this is due to the fact that more stalks are harvestable. Growth retardants, such as trinexapac ethyl, paclobutrazol, etc., which belong to this group, are the most widely used PGR (Rademacher W, 2017). 2) Triazole and strobilurin fungicides that improve disease control and enhance green leaf area (Rolston et al., 2004). Again if the seed yield is higher, it is mainly due to increasing plant vitality rather than controlling flower or seed setting. The application rate for the above mentioned chemicals is between 100 and $200 \mathrm{~g} / \mathrm{ha}$ (Rolston et al., 2004). According to the Grains Research and Development Corporation of the Australian government, which evaluated the results of field trials from 2-3 seasons, the PGR tested slightly increased seed yield in barley but not in wheat (Damian, 2014). 
It is known and well documented that cytokinins help plants to cope with environmental stresses (Hare et al., 1997; Cortleven et al., 2019). Indeed, the CKX inhibitor F-INCYDE improved the tolerance of both rice seedlings and mature plants to heat stress in India (Camblin et al., 2017; Kon et al., 2017). Plants treated with F-INCYDE also had a $6.0-8.8 \%$ higher grain yield. The effects observed in barley and wheat (grain yield increase of 3.0 6.6\%) with 19 were obtained in central Europe with an almost optimal climate for these crops. It is thus possible that application of $\mathbf{1 9}$ could have even better effects in areas with suboptimal conditions. The CKX inhibitors may also show synergistic effects with fertilizers and other agrochemicals used in agriculture because of their different mode of action. However, this remains to be elucidated in future studies.

\section{Conclusion}

In this paper, we present the results of our lab-to-field approach for the development of novel PGR for use in agriculture and biotechnology. Our platform is based on compatible technologies from molecularly targeted organic syntheses through bioassays and in planta testing to field trials. The compounds reported here are very potent urea-based inhibitors of cytokinin oxidase/dehydrogenase (CKX), a key enzyme of cytokinin degradation in plants. The exceptional efficacy of several substances has been shown for four CKX isoforms from two different plant species - Arabidopsis and maize. The ability of compounds $\mathbf{1 9}$ and 21 to inhibit the degradation of cytokinin iP in vivo has been demonstrated in Canadian poplar and tobacco plant tissue cultures. From the results we show that such compounds could find interesting applications in plant biotechnology, for example in the regeneration of species for which this is not yet possible. We further show that CKX inhibitor 19 alleviates stressinduced retardation of Arabidopsis seedlings growth and increases its seed yield. Compound 19 also increased the yield of wheat, barley and rapeseed under field conditions.

It has been shown that GM plants with down-regulated CKX activity provide a significantly higher yield. Furthermore, Ashikari et al. (2005) found that one of the quantitative trait loci in rice is $\operatorname{OsCKX} 2$. The aim of this work is to provide an alternative to these GM plants, i.e. a chemical tool capable of gently and constantly increasing endogenous cytokinin levels in plants. In addition to avoiding legislative obstacles associated with the use of GM organisms, CKX inhibitors offer a number of other benefits. They can be applied to a wide range of plant species and allow flexibility of application with respect to dose and time. Here we present the development of excellent CKX inhibitors which can function in a range of plant species. 


\section{Acknowledgments}

This work was supported by grant $18-07563 \mathrm{~S}$ from the Czech Science Foundation, ERDF grant project No. CZ.02.1.01/0.0/0.0/16_019/0000827 (Plants as a tool for sustainable global development) and grant No. CZ.02.2.69/0.0/0.0/16_027/0008482 from the Ministry of Education, Youth and Sports, Czech Republic. We acknowledge SOLEIL for provision of synchrotron radiation facilities (proposals ID 20160782 and 20170872) in using the Proxima 1 beamline.

\section{Accession numbers}

The atomic coordinates and structure factors of ZmCKX8 with inhibitor $\mathbf{2 0}$ have been deposited in the Protein Data Bank under accession code 6YAQ, and the complexes of ZmCKX4a with 3TFM-2HE (19) and compound 20 are under accession codes 6YAO and 6YAP.

\section{Author Contributions}

J. Nisler, L. Spíchal and M. Strnad designed the research, J. Nisler designed and synthesized all compounds, L. Havlíček and Z. Wimmer assisted with chemical syntheses, R. Končitíková, Z. Pěkná and D. Zalabák contributed to enzyme kinetics, D. Kopečný, P. Briozzo and S. Moréra performed the X-ray crystallographic study, L. Spíchal, Z. Pěkná and N. De Diego performed the cytokinin bioassays and stress alleviation assays, N. Murvanidze and S. Werbrouck performed the plant tissue culture assays, R. Koprna performed the field trials, M. Kopečná and R. Končitíková performed gene expression analysis, J. Nisler evaluated Arabidopsis phenotype and wrote the paper with contributions by co-authors.

\section{Declaration of conflict of interest}

Authors of this manuscript (JN, DK, LS and MS) have filed a Czech patent application (PV 2020-144), which claims the protection of several compounds described in this paper and their use as plant growth regulators. 


\section{References}

Aremu AO, Masondo NA, Sunmonu TO, Kulkarni MG, Zatloukal M, Spichal L, Doležal

K, Van Staden J. 2014. A novel inhibitor of cytokinin degradation (INCYDE) influences the biochemical parameters and photosynthetic apparatus in $\mathrm{NaCl}$-stressed tomato plants. Planta $240,877-889$.

Aremu AO, Stirk WA, Masondo NA et al. 2015. Dissecting the role of two cytokinin analogues (INCYDE and PI-55) on in vitro organogenesis, phytohormone accumulation, phytochemical content and antioxidant activity. Plant Science 238, 81-94.

Arima Y, Oshima K, Shudo K. 1995. Evolution of a novel urea-type cytokinin: horticultural uses of forchlorofenuron. Acta Horticulturae 394, 75-83.

Ashikari M, Sakakibara H, Lin S, Yamamoto T, Takashi T, Nishimura A, Angeles ER, Qian Q, Kitano1 H, Matsuoka M. 2005. Cytokinin oxidase regulates rice grain production. Science 309, 741-745.

Bartrina I, Otto E, Strnad M, Werner T, Schmülling T. 2011. Cytokinin regulates the activity of reproductive meristems, flower organ size, ovule formation, and thus seed yield in Arabidopsis thaliana. Plant Cell 23, 69-80.

Bricogne G, Blanc E, Brandl M et al. (2011) BUSTER version 2.1.0 Cambridge, United Kingdom: Global Phasing Ltd.

Brownlee BG, Hall RH, Whitty CD. 1975. 3-Methyl-2-butenal: an enzymatic degradation product of the cytokinin, $\mathrm{N}-6-($ delta-2 isopentenyl) adenine. Canadian journal of biochemistry $53,37-41$.

Bruce MI, Zwar JA. 1966. Cytokinin activity of some substituted ureas and thioureas. Proceedings of the Royal Society B: Biological Sciences 165, 245-265.

Burch LR, Horgan R. 1989. The purification of cytokinin oxidase from Zea mays kernels. Phytochemistry 28, 1313-1319.

Camblin P, Kon KF, Leipner J, Schmitt N, Thayumanavan AB. 2017. Abiotic stress tolerance. WO 2017/216003.

Camblin P, Pingel A. 2017. Pesticidal compositions. WO 2017/215981.

Chatfield JM, Armstrong DJ. 1986. Regulation of cytokinin oxidase activity in callus tissues of Phaseolus vulgaris L. cv great northern. Plant Physiology 80, 493-499. 
Chen VB, Arendall WB 3rd, Headd JJ, Keedy DA, Immormino RM, Kapral GJ, Murray LW, Richardson JS, Richardson DC. 2010. MolProbity: all-atom structure validation for macromolecular crystallography. Acta Crystallographica Section D Biological Crystallography 66, 12-21.

Cortleven A, Leuendorf JA, Frank M, Pezzetta D, Bolt S, Schmülling T. 2019. Cytokinin action in response to abiotic and biotic stresses in plants. Plant Cell and Environment 42, 9981018 .

D'Agostino IB, Deruere J, Kieber JJ. 2000. Characterization of the response of the Arabidopsis response regulator gene family to cytokinin. Plant Physiology 124, 1706-1717.

Damian J. 2014. https://grdc.com.au/resources-and-publications/grdc-update-papers/tabcontent/grdc-update-papers/2014/07/plant-growth-regulators.

Edgerton MD. 2009. Increasing crop productivity to meet global needs for feed, food, and fuel. Plant Physiology 149, 7-13.

Emsley P, Cowtan K. 2004. Coot: model-building tools for molecular graphics. Acta Crystallographica Section D 60, 2126-2132.

Frébort I, Šebela M, Galuszka P, Werner T, Schmülling T, Peč P. 2002. Cytokinin oxidase/cytokinin dehydrogenase assay: optimized procedures and applications. Analytical Biochemistry 306, 1-7.

Frébortová J, Galuszka P, Werner T, Schmülling T, Frébort I. 2007. Functional expression and purification of cytokinin dehydrogenase from Arabidopsis thaliana (AtCKX2) in Saccharomyces cerevisiae. Biologia Plantarum 51, 673-682.

Galuszka P, Popelková H, Werner T, Frébortová J, Pospíšilová H, Mik V, Köllmer I, Schmülling T, Frébort I. 2007. Biochemical characterization and histochemical localization of cytokinin oxidases/dehydrogenases from Arabidopsis thaliana expressed in Nicotiana tabaccum L. Journal of Plant Growth Regulation 26, 255-267.

Gan S, Amasino RM. 1995. Inhibition of leaf senescence by autoregulated production of cytokinin. Science 270, 1986-1988.

Gan S, Amasino RM. 1997. Making sense of senescence (molecular genetic regulation and manipulation of leaf senescence). Plant Physiology 113, 313-319. 
Gemrotová M, Kulkarni MG, Stirk WA, Strnad M, Van Staden J, Spíchal L. 2013. Seedlings of medicinal plants treated with either a cytokinin antagonist (PI-55) or an inhibitor of cytokinin degradation (INCYDE) are protected against the negative effects of cadmium. Plant Growth Regulation 71, 137-145.

Goldschmidt H, Bardach B. 1892. Zur Kenntniss der Diazoamidokörper. Chemische Berichte 25, 1347-1378.

Guo B, Abbasi BH, Zeb A, Xu LL, Wei YH. 2011 Thidiazuron: A multi-dimensional plant growth regulator. African Journal of Biotechnology 10, 8984-9000.

Hare PD, Cress WA, Van Staden J. 1997. The involvement of cytokinins in plant responses to environmental stress. Plant Growth Regulation 23, 79-103.

Hare PD, Van Staden J. 1994. Inhibitory effect of thidiazuron on the activity of cytokinin oxidase isolated from soybean callus. Plant Cell Physiology 35, 1121-1125.

Holub J, Hanuš J, Hanke DE, Strnad M. 1998. Biological activity of cytokinins derived from ortho- and meta-hydroxybenzyladenine. Plant Growth Regulation 26, 109-115.

Houba-Hérin N, Pethe C, d'Alayer J, Laloue M. 1999. Cytokinin oxidase from Zea mays: purification, cDNA cloning and expression in moss protoplasts. Plant Journal 17, 615-626.

Kabsch W. 2010. XDS. Acta Crystallographica Section D Biological Crystallography 66, $125-132$.

Kabsch W, Sander C. 1983. Dictionary of protein secondary structure: pattern recognition of hydrogen-bonded and geometrical features. Biopolymers 22, 2577-2637.

Kamínek M. 1992. Progress in cytokinin research. TIBTECH 10, 159-164.

Karplus PA, Diederichs K. 2012. Linking crystallographic model and data quality. Science $336,1030-1033$.

Kiba T, Takebayashi Y, Kojima M, Sakakibara H. 2019. Sugar-induced de novo cytokinin biosynthesis contributes to Arabidopsis growth under elevated $\mathrm{CO}_{2}$. Scientific Reports 9:7765.

Kieber JJ, Schaller GE. 2014. Cytokinins. The Arabidopsis Book 12, e0168, doi: 10.1199/tab.0168.

Kon KF, Leipner J, Schmitt N, Thayumanavan AB. 2017. Use of 6-anilino purine derivatives to improve heat stress tolerance of rice seedlings. WO 2017/216005. 
Kopečný D, Briozzo P, Popelková H, et al. 2010. Phenyl- and benzylurea cytokinins as competitive inhibitors of cytokinin oxidase/dehydrogenase: a structural study. Biochimie 92, $1052-1062$.

Kopečný D, Končitíková R, Popelka H, et al. 2016. Kinetic and structural investigation of the cytokinin oxidase/dehydrogenase active site. The FEBS Journal 283, 361-77.

Kopečný D, Pethe C, Šebela M, Houba-Hérin N, Madzak C, Majira A, Laloue M. 2005. High-level expression and characterization of Zea mays cytokinin oxidase/dehydrogenase in Yarrowia lipolytica. Biochimie 87, 1011-1022.

Kopečný D, Tarkowski P, Majira A, Bouchez-Mahiout I, Nogué F, Laurière M, Sandberg G, Laloue M, Houba-Hérin N. 2006. Probing cytokinin homeostasis in Arabidopsis thaliana by constitutively overexpressing two forms of the maize cytokinin oxidase/dehydrogenase 1 gene. Plant Science 171, 114-122.

Koprna R, De Diego N, Dundálková L, Spíchal L. 2015. Use of cytokinins as agrochemicals. Bioorganic \& Medicinal Chemistry 24, 484-492.

Krissinel E, Henrick K. 2004. Secondary-structure matching (SSM), a new tool for fast protein structure alignment in three dimensions. Acta crystallographica. Section D, Biological crystallography 60, 2256-68.

Kurita K, Matsumura T, Iwakura Y. 1976. Trichloromethyl chloroformate. Reaction with amines, amino acids, and amino alcohols. The Journal of Organic Chemistry 41, 2070-2071.

Kutsokon N, Libantova J, Rudas V, Rashydov N, Grodzinsky D, Durechová D. 2013. Advancing protocols for poplars in vitro propagation, regeneration and selection of transformants. The Journal of Microbiology, Biotechnology and Food Sciences 2, 1447-1454.

Lu CY. 1993. The use of thidiazuron in tissue culture. In Vitro Cellular \& Developmental Biology - Plant 29, 92-96.

Malito E, Coda A, Bilyeu KD, Fraaije MW, Mattevi A. 2004. Structures of Michaelis and product complexes of plant cytokinin dehydrogenase: implications for flavoenzyme catalysis. Journal of Molecular Biology 341, 1237-1249.

Morris RO, Bilyeu KD, Laskey JG, Cheikh NN. 1999. Isolation of a gene encoding a glycosylated cytokinin oxidase from maize. Biochemical and Biophysical Research Communications 255, 328-333. 
Nisler J. 2018. TDZ: Mode of Action, Use and Potential in Agriculture. In: Ahmad N., Faisal M. (eds) Thidiazuron: From Urea Derivative to Plant Growth Regulator. Springer, Singapore.

Nisler J, Kopečný D, Končitíková R, Zatloukal M, Bazgier V, Berka K, Zalabák D, Briozzo P, Strnad M, Spíchal L. 2016. Novel thidiazuron-derived inhibitors of cytokinin oxidase/dehydrogenase. Plant Molecular Biology 92, 235-48.

Okamoto T, Shudo K, Takahashi S, Kawachi E, Isogai Y. 1981. 4-Pyridylureas are surprisingly potent cytokinins. The structure-activity relationship. Chemical and Pharmaceutical Bulletin 29, 3748-3750.

Rademacher W. 2017. Chemical regulators of gibberellin status and their application in plant production. In Annual Plant Reviews online, J.A. Roberts (Ed.). doi:10.1002/9781119312994. apr0541

Redig P, Shaul O, Inze D, Van Montagu M, Van Onckelen H. 1996. Levels of endogenous cytokinins, indole-3-acetic acid and abscisic acid during the cell cycle of synchronized tobacco BY-2 cells. FEBS Letters 391, 175-180.

Rolston MP, McCloy BL, Pyke NB. 2004 Grass seed yields increased with plant growth regulators and fungicides. Proceedings of the New Zealand Grassland Association 66, 127132.

Romanov GA, Kieber JJ, Schmülling T. 2002. A rapid cytokinin response assay in Arabidopsis indicates a role for phospholipase D in cytokinin signalling. FEBS Letters 515, 39-43.

Schmülling T, Werner T, Riefler M, Krupkova E, Bartrina Y, Manns I. 2003. Structure and function of cytokinin oxidase/dehydrogenase genes of maize, rice, Arabidopsis and other species. Journal of Plant Research 116, 241-252.

Spíchal L, Rakova NY, Riefler M, Mizuno T, Romanov GA, Strnad M, Schmülling T. 2004. Two cytokinin receptors of Arabidopsis thaliana, CRE1/AHK4 and AHK3, differ in their ligand specificity in a bacterial assay. Plant Cell Physiology 45, 1299-1305.

Storoni LC, McCoy AJ, Read RJ. 2004. Likelihood-enhanced fast rotation functions. Acta Crystallographica Section D Biological Crystallography 60, 432-438.

Suttle JC. 1985. Involvement of ethylene in the action of the cotton defoliant thidiazuron. Plant Physiology 78, 272-276. 
Suttle JC. 1986. Cytokinin-induced ethylene biosynthesis in non-senescing cotton leaves. Plant Physiology 82, 930-935.

Šmehilová M, Galuszka P, Bilyeu KD, Jaworek P, Kowalska M, Šebela M, Sedlářová M, English JT, Frébort I. 2009. Subcellular localization and biochemical comparison of cytosolic and secreted cytokinin dehydrogenase enzymes from maize. Journal of Experimental Botany 60, 2701-2712.

Takahashi S, Shudo K, Okamoto T, Yamada K, Isogai Y. 1978. Cytokinin activity of $N$ phenyl- $N^{\prime}$-(4-pyridyl)urea derivatives. Phytochemistry 17, 1201-1207.

Terrine C, Laloue M. 1980. Kinetics of $N^{6}$-( $\Delta^{2}$-isopentenyl)adenosine degradation in tobacco cells: evidence of regulatory mechanism under the control of cytokinins. Plant Physiology 65, 1090-1095.

Ugena L, Hýlová A, Podlešáková K, Humplík J, Doležal K, Diego N, Spíchal L. 2018. Characterization of biostimulant mode of action using novel multi-trait high-throughput screening of Arabidopsis germination and rosette growth. Frontiers in Plant Science 9, 1327.

Vyroubalová Š, Václavíková K, Turečková V, Novák O, Šmehilová M, Hluska T, Ohnoutková L, Frébort I, Galuszka P. 2009. Characterization of new maize genes putatively involved in cytokinin metabolism and their expression during osmotic stress in relation to cytokinin levels. Plant Physiology 151, 433-447.

Werner T, Motyka V, Laucou V, Smets R, Van Onckelen H, Schmülling T. 2003. Cytokinin-deficient transgenic Arabidopsis plants show multiple developmental alterations indicating opposite functions of cytokinins in the regulation of shoot and root meristem activity. Plant Cell 15, 2532-2550.

Whitty CD, Hall RH. 1974. A cytokinin oxidase in Zea mays. Canadian journal of biochemistry $52,789-799$.

Wuts PGM, Greene TW. 1991. Greene's protective groups in organic synthesis, 4th edition, Wiley, New York.

Zalabák D, Galuszka P, Mrízová K, Podlešáková K, Gu R, Frébortová J. 2014. Biochemical characterization of the maize cytokinin dehydrogenase family and cytokinin profiling in developing maize plantlets in relation to the expression of cytokinin dehydrogenase genes. Plant Physiology and Biochemistry 74, 283-293. 
Zalewski W, Galuszka P, Gasparis S, Orczyk W, Nadolska-Orczyk A. (2010) Silencing of the $H v C K X 1$ gene decreases the cytokinin oxidase/dehydrogenase level in barley and leads to higher plant productivity. Journal of Experimental Botany 61, 1839-51.

Zatloukal M, Gemrotová M, Doležal K, Havlíček L, Spíchal L, Strnad M. 2008. Novel potent inhibitors of A. thaliana cytokinin oxidase/dehydrogenase. Bioorganic \& Medicinal Chemistry 16, 9268-9275. 
Table 1. Structures of CPPU, DCPPU and 3,5DCl-Ph-U (1-(3,5-dichlorophenyl)-3phenylurea) derivatives prepared and overview of their $I C_{50}$ values measured with four $\mathrm{CKX}$ isoforms. Structural formulas and positions of substituents within each urea compound are shown in Figures 1B and 1C respectively. Errors show SD of at least two parallel assays, each consisting of two replicates.

\begin{tabular}{|c|c|c|c|c|c|}
\hline \multicolumn{2}{|c|}{ CPPU and DCPPU derivatives } & \multicolumn{4}{|c|}{$I C_{50}(\mu \mathrm{M})$} \\
\hline Compound & R substituents & AtCKX2 & ZmCKX1 & $\mathrm{ZmCKX} 4 \mathrm{a}$ & $\mathrm{ZmCKX8}$ \\
\hline CPPU & $\mathrm{R} 1-\mathrm{H}, \mathrm{R} 2-\mathrm{H}$ & $56 \pm 3$ & $20.5 \pm 1.1$ & $7.6 \pm 0.6$ & $1.6 \pm 0.1$ \\
\hline 1 & $\mathrm{R} 1-\mathrm{H}, \mathrm{R} 2-2-\mathrm{CH}_{2} \mathrm{CH}_{2} \mathrm{OH}$ & $4.7 \pm 0.2$ & $1.3 \pm 0.2$ & & $1.8 \pm 0.02$ \\
\hline 2 & $\mathrm{R} 1-\mathrm{H}, \mathrm{R} 2-3-\mathrm{OCH}_{3}$ & $64 \pm 4$ & $7.0 \pm 0.2$ & & - \\
\hline 3 & R1 - H, R2 - 3Cl (pyridin-4-yl) & $31 \pm 2$ & $6.6 \pm 0.1$ & & - \\
\hline DCPPU & $\mathrm{R} 1-\mathrm{Cl}, \mathrm{R} 2-\mathrm{H}$ & $2.7 \pm 0.21$ & $4.5 \pm 0.1$ & $2.2 \pm 0.2$ & $0.25 \pm 0.01$ \\
\hline 4 & $\mathrm{R} 1-\mathrm{Cl}, \mathrm{R} 2-2-\mathrm{CH}_{2} \mathrm{CH}_{2} \mathrm{OH}$ & $0.8 \pm 0.1$ & $0.43 \pm 0.06$ & $3.9 \pm 0.3$ & $0.49 \pm 0.02$ \\
\hline 5 & $\mathrm{R} 1-\mathrm{Cl}, \mathrm{R} 2-3-\mathrm{OCH}_{3}$ & $17 \pm 2$ & $0.68 \pm 0.03$ & $3.7 \pm 0.1$ & $2.2 \pm 0.2$ \\
\hline \multicolumn{6}{|c|}{ 3,5DCl-Ph-U derivatives } \\
\hline 6 & $\mathrm{R} 1-\mathrm{H}$ & $2.1 \pm 0.14$ & $0.84 \pm 0.06$ & $1.3 \pm 0.2$ & $0.54 \pm 0.01$ \\
\hline 7 & $\mathrm{R} 1-\mathrm{CH}_{2} \mathrm{NH}_{2}$ & $8.4 \pm 0.07$ & $8.1 \pm 0.7$ & - & - \\
\hline 8 & $\mathrm{R} 1-\mathrm{CH}_{2} \mathrm{OH}$ & $0.23 \pm 0.01$ & $0.40 \pm 0.03$ & $1.7 \pm 0.1$ & $1.2 \pm 0.023$ \\
\hline 9 & $\mathrm{R} 1-\mathrm{COOH}$ & $28 \pm 1.4$ & $1.4 \pm 0.3$ & - & - \\
\hline 10 & $\mathrm{R} 1-\mathrm{CH}_{2} \mathrm{CH}_{2} \mathrm{Cl}$ & $4.2 \pm 0.5$ & $5.6 \pm 0.3$ & - & - \\
\hline 11 & $\mathrm{R} 1-\mathrm{CH}_{2} \mathrm{CH}_{2} \mathrm{NH}_{2}$ & $20 \pm 2$ & $1.5 \pm 0.28$ & - & - \\
\hline 12 & $\mathrm{R} 1-\mathrm{CH}_{2} \mathrm{CH}_{2} \mathrm{OH}$ & $0.11 \pm 0.01$ & $0.18 \pm 0.01$ & $2.5 \pm 0.5$ & $0.33 \pm 0.014$ \\
\hline 13 & $\mathrm{R} 1-\mathrm{CH}_{2} \mathrm{COOH}$ & $175 \pm 25$ & $16 \pm 1$ & - & - \\
\hline 14 & $\mathrm{R} 1-\mathrm{CH}_{2} \mathrm{CONH}_{2}$ & $30 \pm 4.2$ & $0.69 \pm 0.01$ & - & - \\
\hline 15 & $\mathrm{R} 1--\mathrm{CH}_{2} \mathrm{CH}_{2^{-}}$ & $5.1 \pm 0.35$ & $0.74 \pm 0.01$ & - & - \\
\hline
\end{tabular}


Table 2. Structures of 3TFM-Ph-U (1-phenyl-3-(3-(trifluoromethoxy)phenyl)urea) and Ph-2HE-U (1-(2-(2-hydroxyethyl)phenyl)-3-phenylurea) derivatives prepared and overview of their $I C_{50}$ values measured with four CKX isoforms. Structural formulas and positions of substituents within each urea compound are shown in Figures 1D and 1E respectively. Errors show SD of at least two parallel assays, each consisting of two replicates.

\begin{tabular}{|c|c|c|c|c|c|}
\hline \multicolumn{2}{|c|}{ 3TFM-Ph-U derivatives } & \multicolumn{4}{|c|}{$I C_{50}(\mu \mathrm{M})$} \\
\hline Comp. & R substituents & AtCKX2 & $\mathrm{ZmCKX1}$ & $\mathrm{ZmCKX} 4 \mathrm{a}$ & $\mathrm{ZmCKX8}$ \\
\hline 16 & $\begin{array}{l}\mathrm{R} 1-\mathrm{H}, \\
\mathrm{R} 2-\mathrm{CH}_{2} \mathrm{OH}\end{array}$ & $0.2 \pm 0.01$ & $1.1 \pm 0.07$ & $8.1 \pm 0.3$ & $4.1 \pm 0.1$ \\
\hline 17 & $\begin{array}{l}\text { R1 - H, } \\
\text { R2 - CH(OH)CH} 3\end{array}$ & $13 \pm 0.7$ & $1.7 \pm 0.1$ & & \\
\hline 18 & $\begin{array}{l}\mathrm{R} 1-\mathrm{H}, \\
\mathrm{R} 2-\mathrm{CH}_{2} \mathrm{OCH}_{3}\end{array}$ & $3.5 \pm 0.5$ & $5.5 \pm 0.7$ & & - \\
\hline 19 & $\begin{array}{l}\mathrm{R} 1-\mathrm{H}, \\
\mathrm{R} 2-\mathrm{CH}_{2} \mathrm{CH}_{2} \mathrm{OH}\end{array}$ & $0.23 \pm 0.01$ & $0.10 \pm 0.01$ & $5 \pm 0.07$ & $0.19 \pm 0.01$ \\
\hline 20 & $\begin{array}{l}\mathrm{R} 1-\mathrm{Cl}, \\
\mathrm{R} 2-\mathrm{CH}_{2} \mathrm{CH}_{2} \mathrm{OH}\end{array}$ & $0.025 \pm 0.004$ & $0.058 \pm 0.002$ & $0.37 \pm 0.08$ & $0.059 \pm 0.004$ \\
\hline 21 & $\begin{array}{l}\mathrm{R} 1-\mathrm{Br} \\
\mathrm{R} 2-\mathrm{CH}_{2} \mathrm{CH}_{2} \mathrm{OH}\end{array}$ & $0.033 \pm 0.003$ & $0.035 \pm 0.003$ & $0.25 \pm 0.07$ & $\mathbf{0 . 0 3 0} \pm \mathbf{0 . 0 0 2}$ \\
\hline 22 & $\begin{array}{l}\mathrm{R} 1-\mathrm{NHCH}_{2} \mathrm{CH}_{2} \mathrm{OH} \\
\mathrm{R} 2-\mathrm{CH}_{2} \mathrm{CH}_{2} \mathrm{OH}\end{array}$ & $0.064 \pm 0.007$ & $0.029 \pm 0.005$ & $1.5 \pm 0.04$ & $0.61 \pm 0.08$ \\
\hline & 2HE-U derivatives & & & & \\
\hline 23 & $\begin{array}{l}\mathrm{R} 1-3-\mathrm{COOH} \\
\mathrm{R} 2-5-\mathrm{Cl}\end{array}$ & $2.4 \pm 0.2$ & $11 \pm 1$ & $34.3 \pm 6.7$ & - \\
\hline 24 & $\begin{array}{l}\mathrm{R} 1-3-\mathrm{OCH}_{3} \\
\mathrm{R} 2-5-\mathrm{Cl}\end{array}$ & 1 & $0.18 \pm 0.01$ & $10.8 \pm 9$ & $0.78 \pm 0.04$ \\
\hline 25 & $\begin{array}{l}\mathrm{R} 1-3-\mathrm{OCH}_{3} \\
\mathrm{R} 2-5-\mathrm{OCH}_{3}\end{array}$ & 0.03 & $1.0 \pm 0.06$ & - & - \\
\hline 26 & $\begin{array}{l}\mathrm{R} 1-3-\mathrm{CH}_{2} \mathrm{OH} \\
\mathrm{R} 2-5-\mathrm{Cl}\end{array}$ & $0.69 \pm 0.05$ & $0.73 \pm 0.01$ & $14.5 \pm 0.6$ & - \\
\hline 27 & $\begin{array}{l}\mathrm{R} 1-2-\mathrm{CH}_{2} \mathrm{OH} \\
\mathrm{R} 2-5-\mathrm{Cl}\end{array}$ & $1.5 \pm 0.07$ & $0.6 \pm 0.03$ & - & - \\
\hline 28 & $\mathrm{R} 1-2-\mathrm{OCF}_{3}$ & $80 \pm 4$ & $16 \pm 3$ & - & - \\
\hline 29 & $\mathrm{R} 1-4-\mathrm{OCF}_{3}$ & $16 \pm 1.5$ & $5.1 \pm 0.4$ & - & - \\
\hline 30 & $\mathrm{R} 1-3-\mathrm{SCF}_{3}$ & $0.13 \pm 0.01$ & $0.074 \pm 0.001$ & $0.82 \pm 0.18$ & $0.54 \pm 0.008$ \\
\hline 31 & $\mathrm{R} 1-3-\mathrm{CH}_{2} \mathrm{OCF}_{3}$ & $1.0 \pm 0.03$ & $1.0 \pm 0.01$ & $3.5 \pm 0.2$ & - \\
\hline 32 & $\mathrm{R} 1-3-\mathrm{OCF}_{3}$, thiourea & - & $80 \pm 15$ & - & - \\
\hline
\end{tabular}


Table 3. Overview of the inhibitory strengths of known CKX inhibitors and comparison with the most potent CKX inhibitors from this work. Errors show SD of at least two parallel assays, each consisting of two replicates.

\begin{tabular}{lcccc}
\hline & & \multicolumn{3}{c}{$\boldsymbol{I} \boldsymbol{C}_{\mathbf{5 0}}(\boldsymbol{\mu M})$} \\
Compound & AtCKX2 & ZmCKX1 & ZmCKX4a & ZmCKX8 \\
\hline TDZ & $62 \pm 6$ & $44.3 \pm 2.7$ & $223 \pm 25$ & $4.6 \pm 0.1$ \\
CPPU & $56 \pm 3$ & $20.5 \pm 1.1$ & $7.6 \pm 0.6$ & $1.6 \pm 0.1$ \\
DCPPU & $2.7 \pm 0.2$ & $4.5 \pm 0.2$ & $2.2 \pm 0.1$ & $0.25 \pm 0.01$ \\
F-INCYDE & $1.0 \pm 0.2$ & $0.6 \pm 0.1$ & $17 \pm 4$ & $0.18 \pm 0.02$ \\
2HE-TDZ & $3.9 \pm 0.6$ & $2.8 \pm 0.5$ & $136 \pm 8$ & $0.50 \pm 0.02$ \\
3 TFM-TDZ & $5.5 \pm 0.6$ & $4.8 \pm 0.3$ & $39.4 \pm 1.4$ & $0.32 \pm 0.02$ \\
$\mathbf{3 T F M - 2 H E ~ ( 1 9 )}$ & $\mathbf{0 . 2 3} \pm \mathbf{0 . 0 1}$ & $\mathbf{0 . 1 0} \pm \mathbf{0 . 0 1}$ & $\mathbf{1 . 5} \pm \mathbf{0 . 0 7}$ & $\mathbf{0 . 1 9} \pm \mathbf{0 . 0 1}$ \\
$\mathbf{2 0}$ & $\mathbf{0 . 0 2 5} \pm \mathbf{0 . 0 0 4}$ & $\mathbf{0 . 0 5 8} \pm \mathbf{0 . 0 0 2}$ & $\mathbf{0 . 3 7} \pm \mathbf{0 . 0 8}$ & $\mathbf{0 . 0 5 9} \pm \mathbf{0 . 0 0 4}$ \\
$\mathbf{2 1}$ & $\mathbf{0 . 0 3 3} \pm \mathbf{0 . 0 0 3}$ & $\mathbf{0 . 0 3 5} \pm \mathbf{0 . 0 0 3}$ & $\mathbf{0 . 2 5} \pm \mathbf{0 . 0 7}$ & $\mathbf{0 . 0 3 0} \pm \mathbf{0 . 0 0 2}$ \\
$\mathbf{2 2}$ & $0.064 \pm 0.007$ & $0.029 \pm 0.005$ & $1.5 \pm 0.13$ & $0.61 \pm 0.08$ \\
\hline
\end{tabular}


Table 4. Numbers of adventitious shoots regenerated on tobacco leaf disks as a result of iP interaction with CKX inhibitors 19 and 21. Mean values $( \pm S D)$ followed by the same letter are not significantly different by Duncan's multiple range test $(\mathrm{P} \geq 0.05)$.

\begin{tabular}{|c|c|c|c|c|}
\hline \multirow[b]{2}{*}{ Concentration $(\mu \mathrm{M})$} & \multicolumn{4}{|c|}{ Number of adventitious shoots regenerated } \\
\hline & 0 & 0.01 & 0.1 & 1.0 \\
\hline$i P$ & \multicolumn{4}{|c|}{ Inhibitor 19} \\
\hline 0 & 0 & 0 & 0 & 0 \\
\hline 0.01 & 0 & 0 & $12.2 \pm 1.0 \mathrm{a}$ & $16.6 \pm 1.9 \mathrm{ab}$ \\
\hline 0.1 & $17.7 \pm 3.1 \mathrm{ab}$ & $24.0 \pm 1.7 \mathrm{bcd}$ & $22.9 \pm 1.7 \mathrm{bcd}$ & $27.3 \pm 2.7 \mathrm{cde}$ \\
\hline 1.0 & $30.8 \pm 3.2 \mathrm{de}$ & $21.6 \pm 2.8 \mathrm{bc}$ & $18.8 \pm 4 \mathrm{ab}$ & $30.2 \pm 4 \mathrm{e}$ \\
\hline$i P$ & \multicolumn{4}{|c|}{ Inhibitor 21} \\
\hline 0 & 0 & 0 & 0 & 0 \\
\hline 0.01 & 0 & $0.8 \pm 0.4 \mathrm{a}$ & $2.7 \pm 1.4 \mathrm{a}$ & $8.2 \pm 2.1 \mathrm{ab}$ \\
\hline 0.1 & $10.2 \pm 2.5 \mathrm{ab}$ & $13 \pm 1.7 \mathrm{abc}$ & $26.2 \pm 5.4 \mathrm{~cd}$ & $20.6 \pm 8.5 \mathrm{bcd}$ \\
\hline 1.0 & $18.3 \pm 1.9 \mathrm{bc}$ & $18 \pm 2.0 \mathrm{bc}$ & $21.5 \pm 3.2 \mathrm{bcd}$ & $33.3 \pm 2.7 \mathrm{~d}$ \\
\hline
\end{tabular}


Table 5. The effect of foliar and seed application of compound 19 on yield parameters in spring barley, winter wheat and winter rapeseed. Yield in tons per hectare was determined at a grain moisture level of 14\%. Grain yield is average from six experimental plots. Number of tillers represents strong and medium tillers combined and is an average from 50 - 60 plants. Foliar application was performed with $5 \mu \mathrm{M}$ solution. BBCH stands for the BBCH-scale, which describes phenological growth stages of individual crops.

\begin{tabular}{lccc}
\hline Year / type of application & $\begin{array}{c}\text { Yield } \\
(\% \text { of control })\end{array}$ & $\begin{array}{c}\text { TGW } \\
(\% \text { of control })\end{array}$ & $\begin{array}{c}\text { Number of tillers } \\
(\% \text { of control })\end{array}$ \\
\hline Barley & +3.0 & +1.8 & +9.8 \\
2016 / seed coating $10 \mu \mathrm{M}$ & +0.7 & -4.0 & 0.0 \\
2016 / seed coating 50 $\mu \mathrm{M}$ & +6.3 & & -10.0 \\
2017 / foliar application at BBCH 21-23 & +6.4 & - & +28.0 \\
2017 / foliar application at BBCH 51 & & - & -4.7 \\
\hline Wheat & +4.0 & - & +4.4 \\
2017 / seed coating 50 $\mu \mathrm{M}$ & +6.6 & - & - \\
2018 / seed coating 50 $\mu \mathrm{M}$ & +5.9 & & - \\
2017 / foliar application at BBCH 25 & +5.0 & +3.5 & - \\
2017 / foliar application at BBCH 51 & +5.7 & +5.1 & - \\
\hline Oilseed Rape & +7.5 & & - \\
2017 / foliar application at BBCH 30 & +535 & & \\
2017 / foliar application at BBCH 33-35 & & & - \\
\hline
\end{tabular}




\section{List of legends}

Figure 1. (A) Structures of two previously described CKX inhibitors (black, Nisler et al., 2016) and two new CKX inhibitors (pink and purple) from this work. A combination of parts of molecules that are shown in black and bold gave rise to compound 19. (B-E) General structures of prepared derivatives 1-31. (F) Quantitative evaluation of the cytokinin activities of the compounds in ARR5:GUS assays. Their activity is compared to that of $1 \mu \mathrm{M} N^{6}$ benzyladenine (BA), which was set as $100 \%$ activation (dashed line). DMSO (0.1\%) was used as solvent control (dotted line). Error bars show SD of two parallel assays, each consisting of two replicates. (G) The effect of iP, compound 21 and combinations thereof on adventitious shoot induction from tobacco leaf disks. The image corresponds with data in Table 4. Last line for $1 \mu \mathrm{M}$ iP is omitted from the picture. (H) The effect of compound 19 on growth (presented as green area) of Arabidopsis seedlings grown under stress. Error bars show SD of the mean for five replicate determinations. (I) De novo organogenesis on poplar leaf explant four weeks after incubation.

Figure 2. (A) Concentration-dependent curves of residual CKX activity for known CKX inhibitors and for inhibitors 19 and 20. (B-E) Binding of inhibitors 19 and 20 at the active site of CKX. (B) Omit electron density map for inhibitor 19 (3TFM-2HE, pink color) in ZmCKX4a. The FAD molecule is shown in yellow and other atoms are color-coded. (C) Superposition of bound substrate iP (green, Malito et al., 2004) and inhibitor 19 (pink) on ZmCKX1 (green) and ZmCKX4a (grey), respectively. (D, E) Omit electron density evidence for bound inhibitor $\mathbf{2 0}$ (violet) in $\mathrm{ZmCKX} 4 \mathrm{a}$ and $\mathrm{ZmCKX} 8$. The mesh represents a simulated annealing $F_{\mathrm{o}}-F_{\mathrm{c}}$ omit map contoured at $3 \sigma$. 
Figure 1

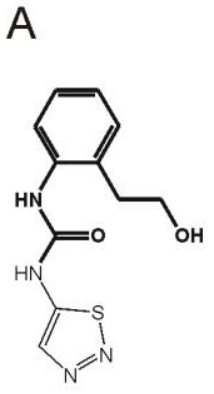

2HE-TDZ

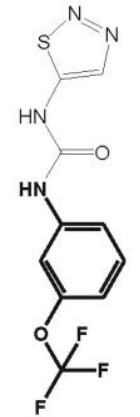

3TFM-TDZ

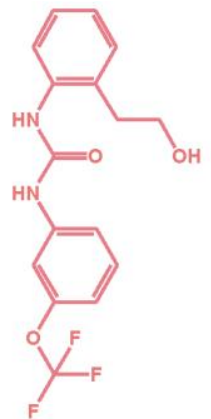

3TFM-2HE (compound 19)

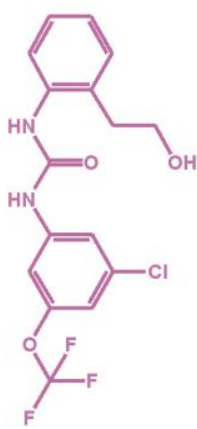

compound 20<smiles>[R2]c1ccc(NC(=O)Nc2cc([R1])nc(Cl)c2)cc1</smiles><smiles>[R1]c1cc(NC(=O)Nc2ccccc2[R2])cc(OC(F)(F)F)c1</smiles>

compounds 16 - 22

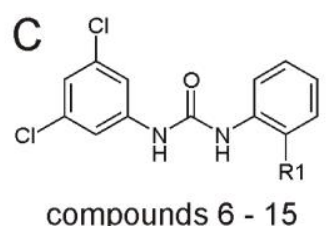

E

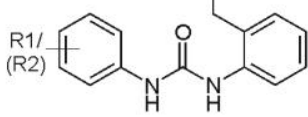

compounds 23 - 31
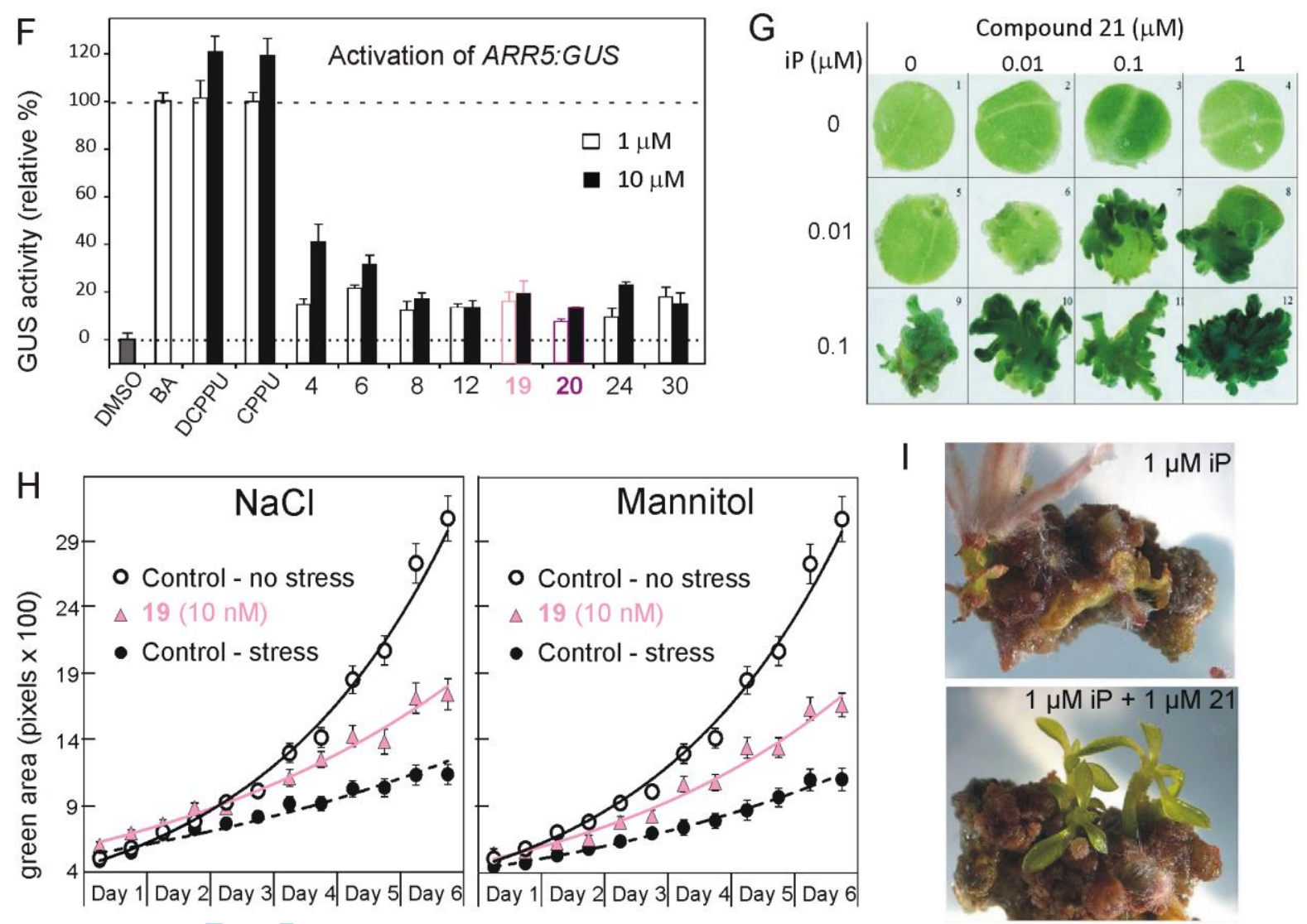
Figure 2.
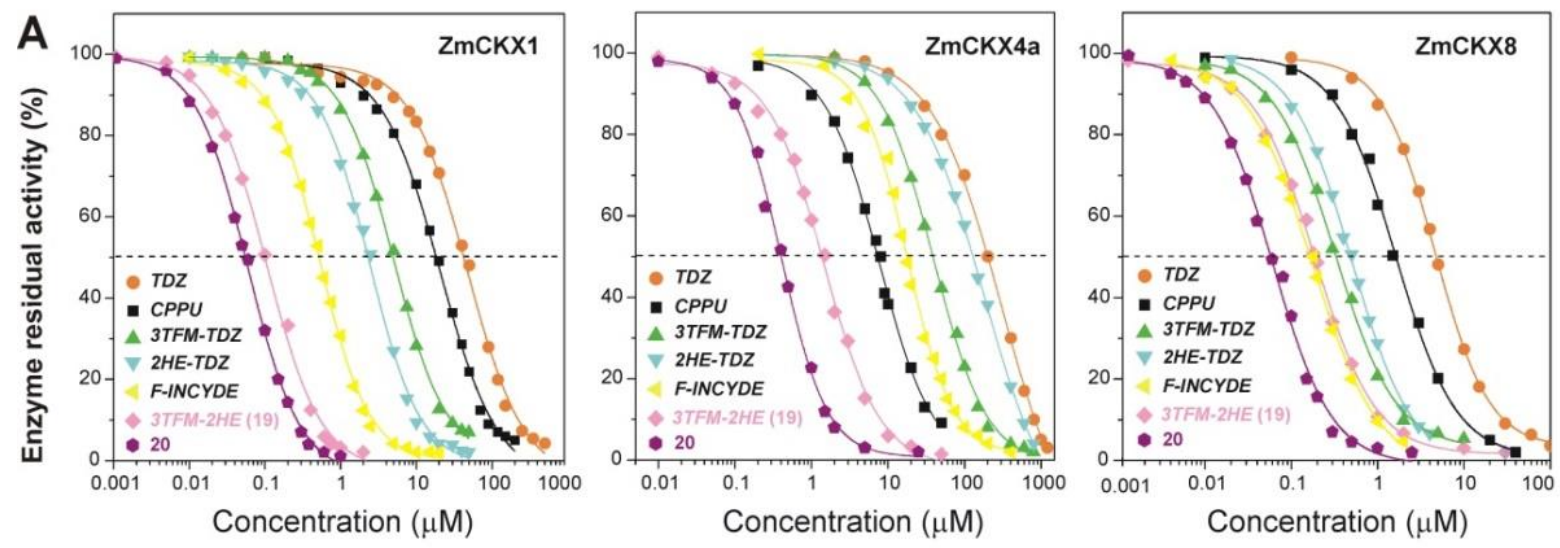

B ZmCKX4a + 3TFM-2HE (19)

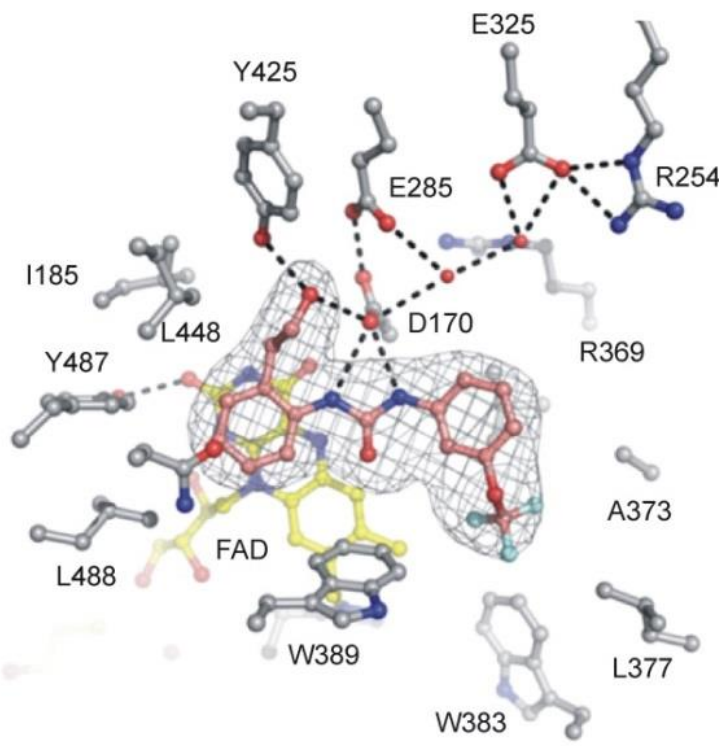

D $\quad \mathrm{ZmCKX} 4 \mathrm{a}$ + compound 20

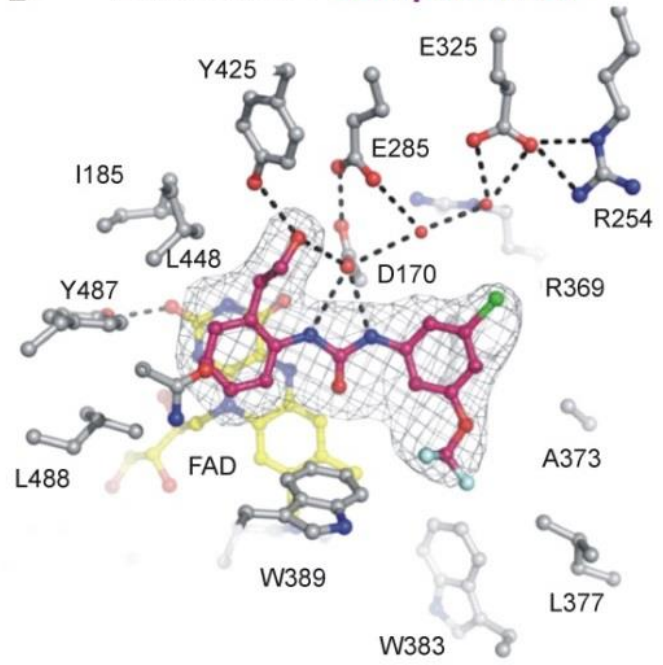

C ZmCKX1/ZmCKX4a + iP I 3TFM-2HE (19)

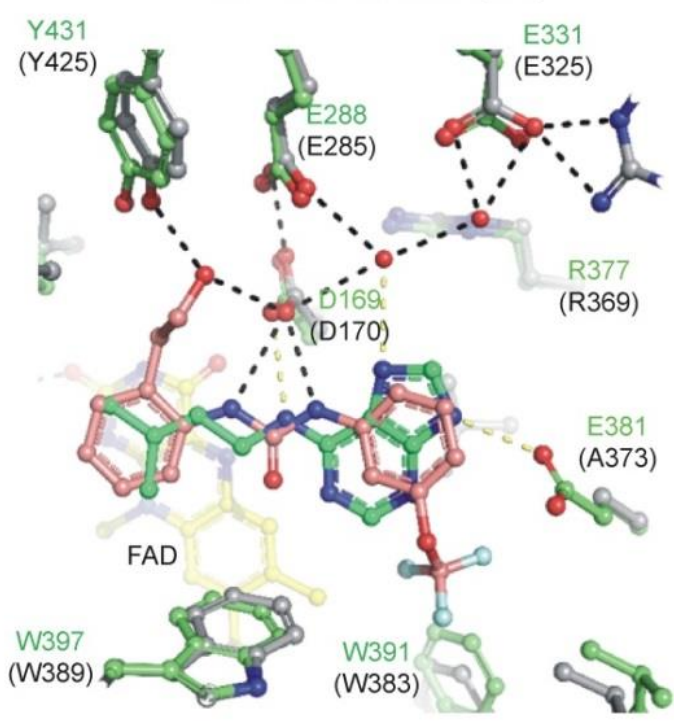

E $\quad$ ZmCKX8 + compound 20

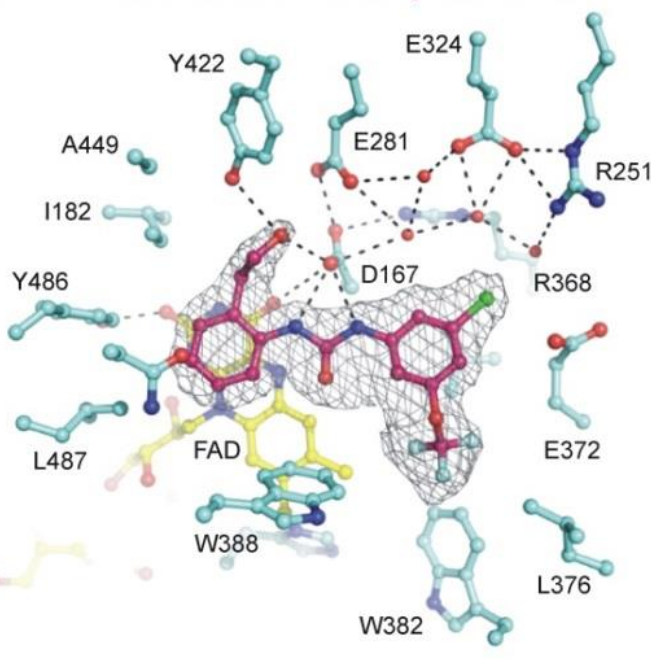

